\title{
Photovoltaic Cell and Module I-V Characteristic Approximation Using Bézier Curves
}

\author{
Roland Szabo ${ }^{1}$ and Aurel Gontean * \\ 1 Applied Electronics Department, Politehnica University Timisoara, Timisoara 300006, Romania; \\ roland.szabo@upt.ro (R.S.); aurel.gontean@upt.ro (A.G.) \\ * Correspondence: aurel.gontean@upt.ro; Tel.: +40-745-121-383
}

\begin{abstract}
The aim of this work is to introduce new ways to model the I-V characteristic of a PV cell or PV module using straight lines and Bézier curves. This is a complete novel approach, Bézier curves being previously used mainly for computer graphics. The I-V characteristic is divided in three sections, modeled with lines and a quadratic Bézier curve in the first case and with three cubic Bézier curves in the second case. The result proves to be accurate and relies on the fundamental points usually present in the PV cell datasheets: $V_{o c}$ (the open circuit voltage), $I_{s c}$ (the short circuit current), $V_{m p}$ (the maximum power corresponding voltage) and $I_{m p}$ (the maximum power corresponding current) and the parasitic resistances $R_{s h 0}$ (shunt resistance at $I_{s c}$ ) and $R_{s 0}$ (series resistance at $V_{o c}$ ). The proposed algorithm completely defines all the implied control points and the error is analyzed. The temperature and irradiance influence is also analyzed. The model is also compared using the least squares fitting method. The final validation shows how to use Bézier cubic curves to accurately represent the I-V curves of an extensive range of PV cells and arrays.
\end{abstract}

Keywords: PV cell; I-V characteristic; model; simulation; interpolation; Bézier curve; control points; least squares fitting method

\section{Introduction}

The forecast of the total PV installs, offered by Bloomberg New Energy Finance (BNEF) predicts an optimistic growth at $111 \mathrm{GW}$ in 2018, rising to $121 \mathrm{GW}$ in 2019, along with a polysilicon factory grow boom and module prices drop to US\$0.30/W [1], [2]. This robust growth explains the high interest in PV research, modeling and simulation - along with design and development of PV equipment.

The electrical characteristics of the PV cell and PV modules have been of interest for several decades, and different models have been proposed. Phang and Chan [3] were among the first to propose a solution for PV cell parameter extraction. Garrido-Alzar [4] uses a double exponential model to extract the PV cell parameters using the experimental I-V curve. Villalva et al. [5] developed an algorithm to find the parameters defining the I-V characteristic for the single diode model of a PV cell, using the Newton-Raphson method and imposing a minimum error threshold for the maximum power point. Babu and Gurjar [6] introduce a simplified two-diode model for the PV module, while Cubas et al. [7] used the Lambert W-Function for finding the solar panel equivalent circuit parameters and they also proposed an LTSpice model according to their findings. Temperature influence is studied by Chander et al. [8]. Ishaque and Salam [9] use differential evolution to find the PV modules parameters.

Franzitta et al. provide extensive studies of the most widely used models both in single diode case [10] and for the double-diode version [11], introducing a criterion for rating the accuracy and usability of the analyzed models. In our previous paper [12], we proposed a complete SPICE model including all the parameters variation and selfheating. In a recent work, Cuce et al. [13] claim a good accuracy for their electrical model for a PV module and they also discuss energy and exergy efficiency as a reliable substitute for the fill factor. All the aforementioned works use an electrical model to describe the behavior of the circuit and rely on a specific circuit to generate the I-V characteristic of the PV cell or module. 
This paper introduces a new approach. This time, the cell or module are not involved at the electrical level, being defined by just the specific points $P_{s c}, P_{m p}, P_{o c}$ and by the parallel and series resistances $R_{s h 0}$ and $R_{s 0}$, specified at $I_{s c}$ and $V_{o c}$, respectively. Carefully inspection of the typical I-V characteristic of the PV module or PV cell (Figure 1a and 1b) shows a similar pattern in all curves. Our aim was to find a way to model it using smooth curves and datasheet information currently available.

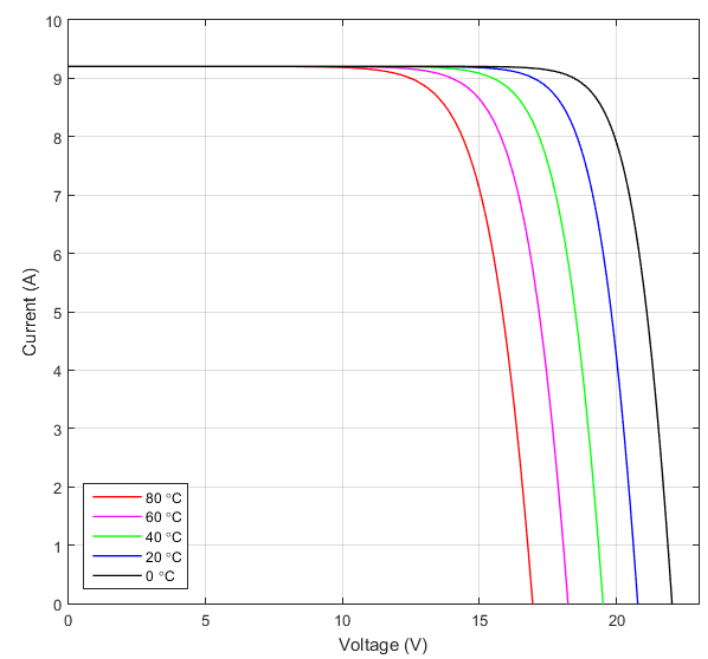

a)

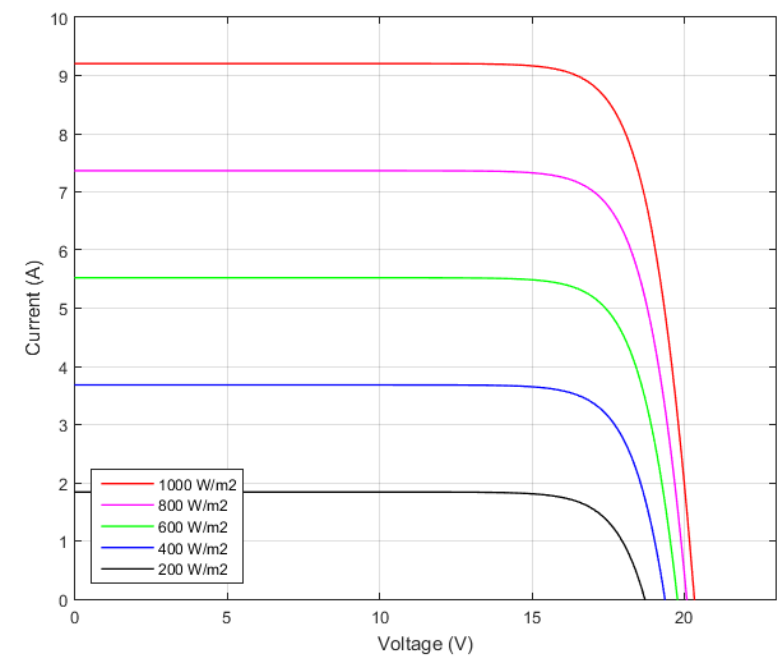

b)

Figure 1. Typical PV module I-V characteristics, with 30 cells connected in series. a) at different temperatures $\left(0-80^{\circ} \mathrm{C}\right)$. b) At different irradiances $\left(200-1000 \mathrm{~W} / \mathrm{m}^{2}\right)$.

Bernstein polynomials have been studied since the beginning of the $20^{\text {th }}$ century and they form the foundation for Bézier curves [14]. The core applications for graphics came first in 1959 when the French mathematician Paul de Casteljau developed an algorithm able to evaluate a family of specific curves at Citroën. In 1962 the French engineer Pierre Bézier also used them to design automobile bodies at Renault and afterwards they got wide acceptance [15].

Bézier curves are largely used in computer graphics $[16,17]$ and also in time domain for smoothing the trajectory of the robotic arms, for an accurate gluing or welding path or for trajectory generation [18]. Further development for shape representation is proposed by Jalba et al. [19].

The current proposal analyses the use of Bézier curves [20] in order to accurately represent the $\mathrm{I}-\mathrm{V}$ characteristic of a PV cell or module. A complete mathematical solution is provided, separately validated for a PV cell and a PV module and the error is analyzed. The results are also studied for different temperature and irradiances and finally compared with the ones offered by the least squares fitting method. In depth analysis of Bézier cubic curves fitting for 18 PV arrays and cells (from various manufacturers and different technologies) is also performed.

The remainder of this paper is organized as follows: Section 2 briefly analyzes the definition of the quadratic and cubic Bézier curves and their equations, focusing on the basic knowledge needed in the subsequent paragraphs. Section 3 deals with the information usually provided by the PV cell or module manufacturers in their datasheets. The proposed models are covered in Section 4, with Section 4.1 introducing the approximation with two segments and one quadratic Bézier curve, while Section 4.2 deals with the better approximation based on three Bézier cubic curves. The models are rated at the reference temperature, $25^{\circ} \mathrm{C}$. The results are also compared with the least squares fitting method in Section 4.3. In Section 4.4 the influence of the external parameters is analyzed. The proposal is verified in Section 4.5 against a large range of PV cells and modules and the results show a good fit. Discussion and conclusions are provided in the next Sections. 


\section{Definition of the Bézier Curves}

A quadratic Bézier curve (Figure 2) can be specified by three control points [15]: the curve goes through the ends $P_{0}$ and $P_{2}$ and approximates $P_{1}$.

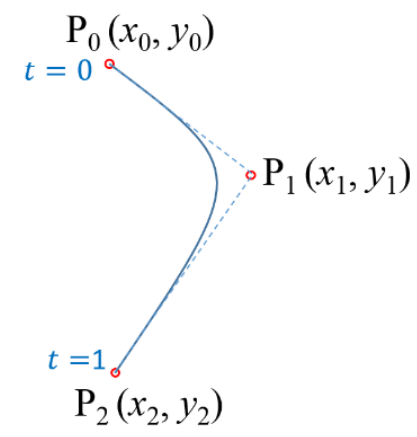

Figure 2. A quadratic Bézier curve representation. $P_{0}$ and $P_{2}$ are the end points, the control point $P_{1}$ is approximated and the curve is tangent to $\overline{P_{0} P_{1}}$ and $\overline{P_{2} P_{1}}$ segments at $P_{0}$ and $P_{2}$ respectively.

The curve equation is as follows [20]:

$$
B_{2}(t)=(1-t)^{2} P_{0}+2 t(1-t) P_{1}+t^{2} P_{2}
$$

where $t$ varies between 0 and 1. Equation (1) can be expressed for the $x$ and $y$ coordinates:

$$
\left\{\begin{array}{l}
x(t)=(1-t)^{2} x_{0}+2 t(1-t) x_{1}+t^{2} x_{2} \\
y(t)=(1-t)^{2} y_{0}+2 t(1-t) y_{1}+t^{2} y_{2}
\end{array}\right.
$$

The derivative of (1) is:

$$
B_{2}^{\prime}(t)=2(1-t)\left(P_{1}-P_{0}\right)+2 t\left(P_{2}-P_{1}\right)
$$

At the end points, (3) becomes (4):

$$
\left\{\begin{array}{l}
\left.B_{2}^{\prime}(t)\right|_{t=0}=2 P_{1}-2 P_{0} \\
\left.B_{2}^{\prime}(t)\right|_{t=1}=2 P_{2}-2 P_{1}
\end{array}\right.
$$

A cubic Bézier curve (Figure 3) can be specified by four control points [15]: the curve goes through the ends $P_{0}$ and $P_{3}$ and approximates $P_{1}$ and $P_{2}$. The analytical expression of the curve is a cubic polynomial. The curve is tangent at $P_{0}$ to $\overline{P_{0} P_{1}}$ and at $P_{3}$ to $\overline{P_{3} P_{2}}$.

The equation for the Bézier cubic curve is [20]:

$$
B_{3}(t)=(1-t)^{3} P_{0}+3 t(1-t)^{2} P_{1}+3 t^{2}(1-t) P_{2}+t^{3} P_{3}
$$

The previous equation can be expressed for the $x$ and $y$ coordinates:

$$
\left\{\begin{array}{l}
x(t)=(1-t)^{3} x_{0}+3 t(1-t)^{2} x_{1}+3 t^{2}(1-t) x_{2}+t^{3} x_{3} \\
y(t)=(1-t)^{3} y_{0}+3 t(1-t)^{2} y_{1}+3 t^{2}(1-t) y_{2}+t^{3} y_{3}
\end{array}\right.
$$

The derivative of (5) is:

$$
B_{3}^{\prime}(t)=3(1-t)^{2}\left(P_{1}-P_{0}\right)+6 t(1-t)\left(P_{2}-P_{1}\right)+3 t^{2}\left(P_{3}-P_{2}\right)
$$

At the end points, (7) becomes (8):

$$
\left\{\begin{array}{l}
\left.B_{3}^{\prime}(t)\right|_{t=0}=3 P_{1}-3 P_{0} \\
\left.B_{3}^{\prime}(t)\right|_{t=1}=3 P_{3}-3 P_{2}
\end{array}\right.
$$




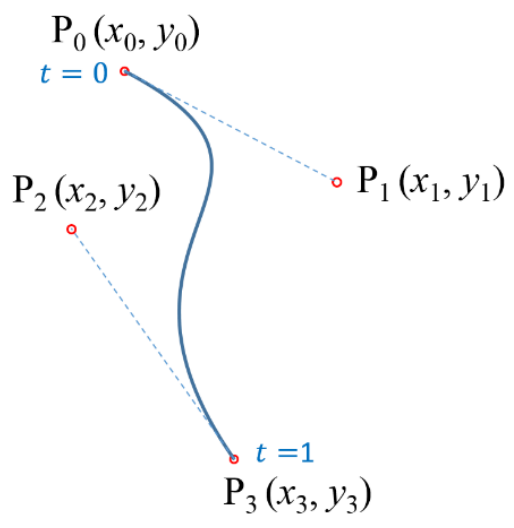

Figure 3. A cubic Bézier curve representation. $P_{0}$ and $P_{3}$ are the end points, the control points $P_{1}$ and $P_{2}$ are approximated and the curve is tangent to $\overline{P_{0} P_{1}}$ and $\overline{P_{2} P_{1}}$ segments at $P_{0}$ and $P_{3}$ respectively.

\section{Materials and Methods}

The first PV cell used in our work is a high efficiency, silicon monocrystalline $156 \times 156 \mathrm{~mm}^{2}$ cell [21] and has the main characteristics summarized in Table 1.

Table 1. PV Cell main specifications on STC $\left(1000 \mathrm{~W} / \mathrm{m}^{2}, \mathrm{AM} 1.5,25^{\circ} \mathrm{C}\right)$.

\begin{tabular}{ccc}
\hline Symbol & Description & Value \\
\hline$V_{o c, \text { cell,ref }}$ & Cell open circuit voltage & $0.699 \mathrm{~V}$ \\
$I_{s c, \text { ref }}$ & Short circuit current & $9.207 \mathrm{~A}$ \\
$V_{m p}$ & Maximum power voltage & $0.572 \mathrm{~V}$ \\
$I_{m p}$ & Maximum power current & $8.756 \mathrm{~A}$ \\
$R_{s h 0}$ & Shunt resistance at $I_{s c}$ & $73.19 \Omega$ \\
$R_{s 0}$ & Series resistance at $V_{o c}$ & $3.8 \mathrm{~m} \Omega$ \\
\hline
\end{tabular}

The MSMD290AS-36_EU Monocrystalline PV module [22] is well documented and studied by Cubas et al. [6]. Its main electrical data is listed in Table 2 and this information will be used in Section 4.4 to evaluate the influence of the temperature and irradiance to our Bézier curves based model.

Table 2. MSMD290AS-36_EU Module main specifications on STC $\left(1000 \mathrm{~W} / \mathrm{m}^{2}\right.$, AM $\left.1.5,25^{\circ} \mathrm{C}\right)$.

\begin{tabular}{ccc}
\hline Symbol & Description & Value \\
\hline$V_{\text {oc,module,ref }}$ & Cell open circuit voltage & $44.68 \mathrm{~V}$ \\
$I_{s c, r e f}$ & Short circuit current & $8.24 \mathrm{~A}$ \\
$V_{m p}$ & Maximum power voltage & $37.66 \mathrm{~V}$ \\
$I_{m p}$ & Maximum power current & $7.70 \mathrm{~A}$ \\
$R_{s h 0}$ & Shunt resistance at $I_{s c}$ & $316 \Omega$ \\
$R_{s 0}$ & Series resistance at $V_{o c}$ & $130 \mathrm{~m} \Omega$ \\
$k_{I}$ & Current temperature coefficient & $3.296 \mathrm{~mA} / \mathrm{K}$ \\
$k_{V}$ & Voltage temperature coefficient & $-146.256 \mathrm{mV} / \mathrm{K}$ \\
$n_{s}$ & Number of series cell & 72 \\
\hline
\end{tabular}

For studying and representing Bézier curves, an interesting application which allows draggable control points was developed by Mugnaini [23]. For computing the coordinates on the curves we used the Kronecker tensor product found as in [24]. An example for Bézier least square fitting method is given in [25]. 


\section{Results}

It must be stressed out that all the physical actual values involved in sections 4.1, 4.2 and 4.3 are specified at $25^{\circ} \mathrm{C}$, being reference values. The irradiance is also standard $\left(1000 \mathrm{~W} / \mathrm{m}^{2}\right)$. As it will be demonstrated in section 4.4., the same method is suitable for different temperatures and irradiances.

\subsection{I-V Characteristic approximation with two segments and a quadratic Bézier Curve}

The first approximation implies five control points: $P_{s c}\left(0, I_{s c}\right), P_{a}\left(x_{a}, y_{a}\right), P_{b}\left(x_{b}, y_{b}\right), P_{c}\left(x_{c}, y_{c}\right)$ and $P_{o c}\left(V_{o c}, 0\right)$ and is made of two segment lines $\overline{I_{s c} P_{a}}$ and $\overline{P_{b} V_{o c}}$ and one quadratic Bézier curve defined by the endpoints $P_{a}$ and $P_{b}$ and the control point $P_{c}$ (figure 4 ).

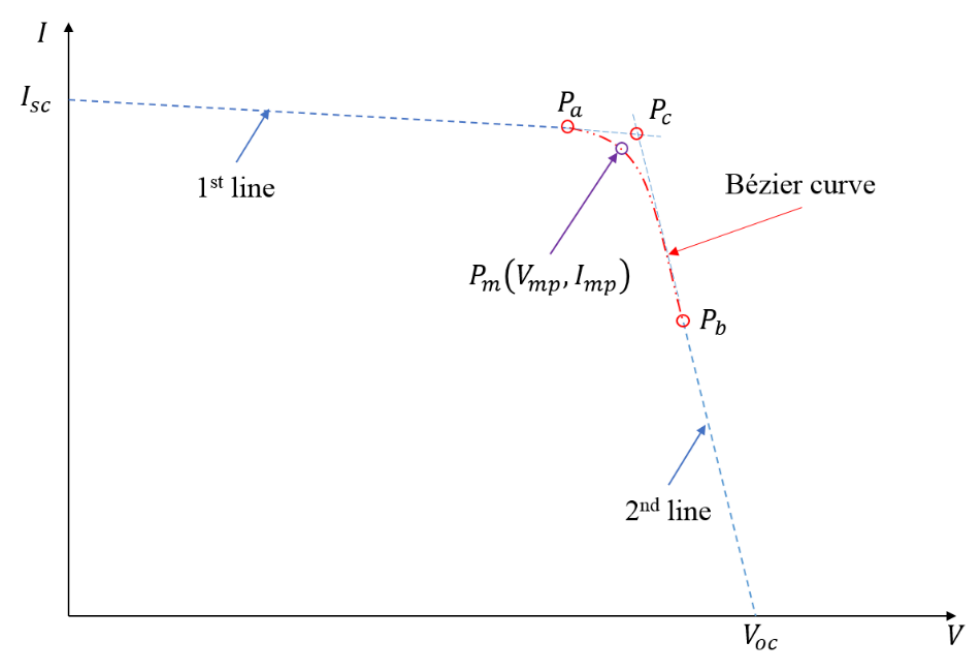

Figure 4. Projected PV cell I-V characteristic approximation with two straight line segments and one quadratic Bézier curve.

It has already been proven [3] that the slopes of the lines can be written as (9) and (10):

$$
\begin{aligned}
& \left.\frac{d I}{d V}\right|_{V=0}=-\frac{1}{R_{s h 0}} \\
& \left.\frac{d I}{d V}\right|_{V=V_{o c}}=-\frac{1}{R_{s 0}}
\end{aligned}
$$

Thus, the equation for first line is (11):

$$
I=I_{s c}-\frac{V}{R_{s h 0}}
$$

By choosing $x_{a}$ in the linear region $\left(\operatorname{eg} 0.6 V_{o c}\right)$, one can find $y_{a}$ from the above equation, so $P_{a}$ is completely defined.

For the second line, the next equation is valid (12):

$$
I=\frac{V_{o c}-V}{R_{s 0}}
$$

The $P_{c}\left(V_{c}, I_{c}\right)$ control point has therefore the coordinates defined by (13):

$$
\left(x_{c}=V_{c}=\frac{V_{o c} R_{s h 0}-I_{s c} R_{s h 0} R_{s 0}}{R_{s h 0}-R_{s 0}}, y_{c}=I_{c}=\frac{I_{s c} R_{s h 0}-V_{o c}}{R_{s h 0}-R_{s 0}}\right)
$$


For $x_{b}$, it must be emphasized that its position is on the end of the curve, a realistic value being $0.9 V_{o c}$. The maximum power point is positioned on the second curve, so solving (14) gives $t_{m p}$ :

$$
t_{m p}^{2}\left(x_{a}+x_{b}-2 x_{c}\right)+2 t_{m p}\left(x_{c}-x_{a}\right)+x_{a}-V_{m p}=0
$$

Replacing the positive solution for $t_{m p}$ in (2) yields $y_{b}$ as in (15):

$$
y_{b}=\frac{\left(2 t_{m p}-t_{m p}^{2}-1\right) y_{a}+2 t_{m p}\left(t_{m p}-1\right) y_{c}+I_{m p}}{t_{m p}^{2}}
$$

Now all the control points of the plot are completely defined. The results are summarized in Table 3. The application code written for the coordinate finding can be found here: http://tess.upt.ro.

Table 3. The control point coordinates when using two lines and one quadratic Bézier curve.

\begin{tabular}{ccc}
\hline Point & $\boldsymbol{x}$ coordinate $(\mathrm{V})$ & $\boldsymbol{y}$ coordinate (A) \\
\hline \multicolumn{3}{c}{ First line segment } \\
$P_{S C}$ & 0 & 9.207 \\
$P_{a}$ & 0.4893 & 9.2003 \\
& Quadratic Bézier Curve \\
$P_{a}$ & 0.4893 & 9.2003 \\
$P_{c}$ & 0.6070 & 9.1987 \\
$P_{b}$ & 0.6291 & 7.0181 \\
& Second line segment \\
$P_{b}$ & 0.6291 & 7.0181 \\
$P_{o c}$ & 0.699 & 0 \\
\hline
\end{tabular}

The final plot is represented in Figure 5, where one can observe an excellent correspondence between the actual PV cell I-V characteristic, represented with black dots and the $\overline{P_{s c} P_{a}}$ segment (blue line), a fair correlation for the second range, approximated by the Bézier quadratic curve (red line) and some modest results in the third region (magenta line).

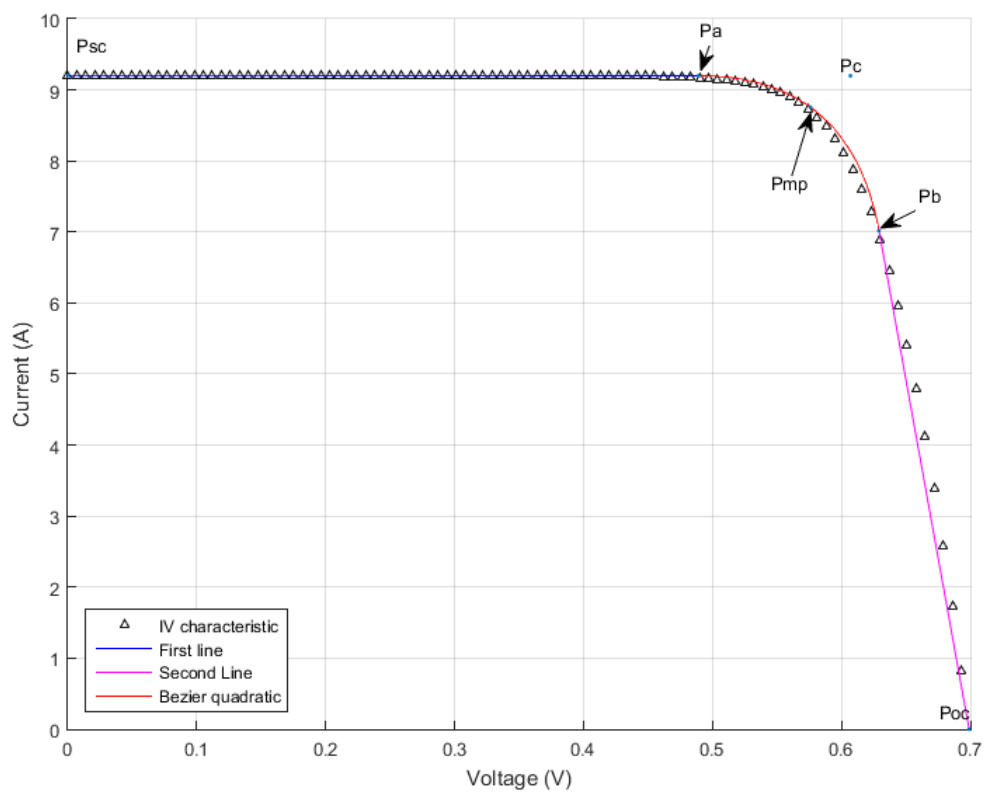

Figure 5. PV cell I-V characteristic approximation with two straight lines and one quadratic Bézier curve - results. 
The same conclusion arises from Figure 6, where the relative error has been plotted. It is worth mentioning that although the relative error is quite high above $0.64 \mathrm{~V}\left(0.92 V_{o c}\right)$, the absolute error is in fact less than $0.7 \mathrm{~A}$ in a region where the cell normally should not operate.

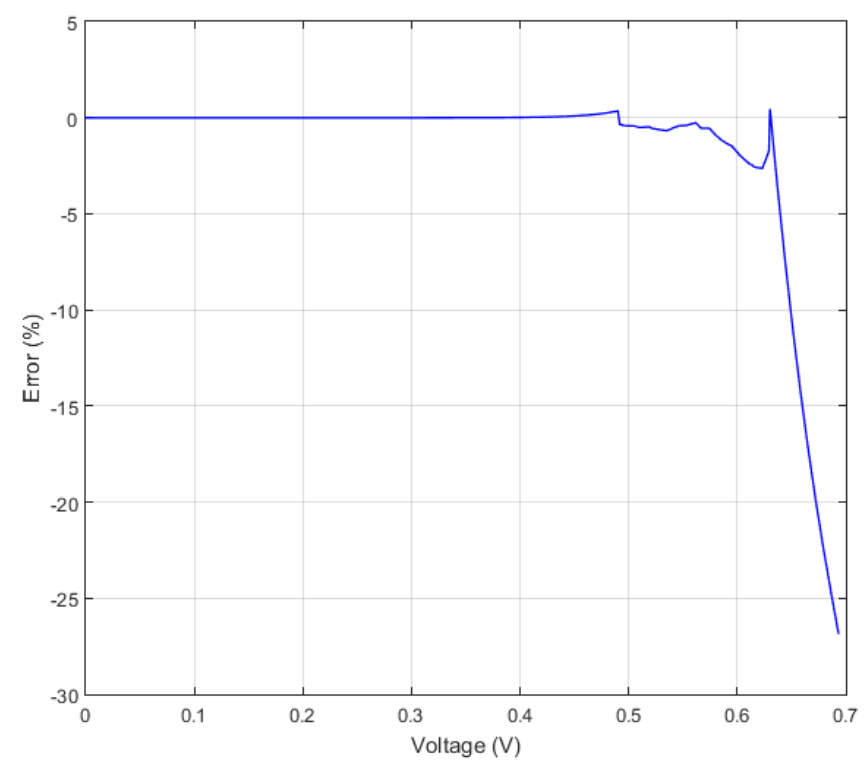

Figure 6. Approximation errors are high over $0.64 \mathrm{~V}$.

Looking for a more accurate model is the reason we came up with the second scenario, where the I-V characteristic is entirely modeled with cubic Bézier curves.

\subsection{I-V Characteristic approximation with three cubic Bézier curves}

In order to have a general solution, we analyzed the case where all three regions are covered with cubic Bézier curves. This implies 12 control points (Figure 7), i.e. 24 coordinates to be found.

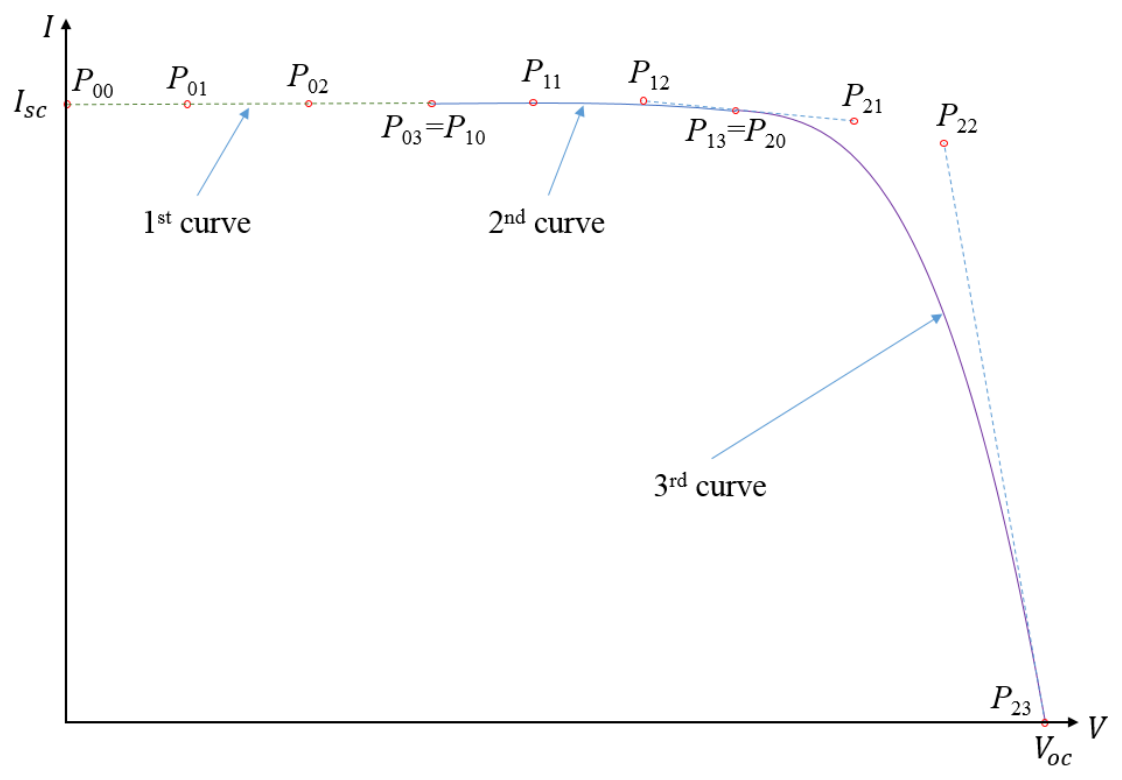

Figure 7. Projected PV cell I-V characteristic approximation with three cubic Bézier curves.

The first curve, represented in Figure 8 , is described by the control points $P_{00}\left(0, I_{s c}\right), P_{01}, P_{02}$ and $P_{03}$. It turns out that the linear approximation of the first region of the I-V curve has an error below $0.5 \%$ if $P_{03 x}=V_{o c} / 2$. During various simulations we have also discovered that all $P_{j, k}$ points can be 
evenly arranged, with $j=\{1,2\} ; k=\{1,2,3\}$. This leads to $P_{01 x}=P_{03 x} / 3$ and $P_{02 x}=2 P_{03 x} / 3$. For the $y$ coordinates, $P_{0 k y}=I_{s c}-{ }^{0} k x / R_{s h 0^{\prime}}$ with $k=\{1,2,3\}$. Now the first curve is completely defined.

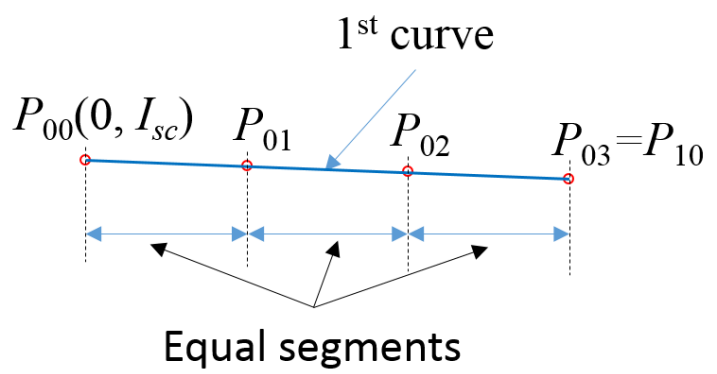

Figure 8. First Bézier curve with the associated control points. The slope is exaggerated for a better understanding.

The second curve (Figure 7) is described by the control points $P_{10}=P_{03}, P_{11}, P_{12}$ and $P_{13}$. We observed that $P_{13 x}=0.75 V_{o c}$ offers a very good fit of the curve for this type of PV cell. With the same evenly arrangement for the $x$ coordinates, $P_{1 k x}=P_{10 x}+k\left(P_{13 x}-P_{10 x}\right) / 3$, with $k=\{1,2\} . P_{11}$ is also located in the linear region of the I-V curve, so $P_{11 y}=P_{03 y}-P_{11 x} / R_{s h 0}$. This leaves $P_{12 y}$ and $P_{13 y}$ as unknowns at this stage.

The third curve (Figure 7) is described by the control points $P_{20}=P_{13}, P_{21}, P_{22}$ and $P_{23}\left(V_{o c}, 0\right)$. Using the same assumptions as for the second curve, $P_{2 k x}=P_{20 x}+k\left(P_{23 x}-P_{20 x}\right) / 3$, with $k=\{1,2\}$. It is obvious that $P_{20 x}=P_{13 x}$ and $P_{23 x}=V_{o c}$. The segment $\overline{P_{22} P_{23}}$ is tangent to the curve at the point $P_{23}$, so $P_{22 y}=\left(V_{o c}-P_{22 x}\right) / R_{s 0}$. This leaves $P_{21 y}$ as an additional unknown at this step.

For continuity reasons, $\overline{P_{12} P_{13}}$ and $\overline{P_{20} P_{21}}$ segments belong to the same line. This implies that the derivatives of the second curve at $P_{13}$ and of the third curve at $P_{20}$ are equal (16):

$$
3 P_{13 y}-3 P_{12 y}=3 P_{21 y}-3 P_{20 y}
$$

Which means that:

$$
P_{21 y}=2 P_{13 y}-P_{12 y}
$$

The control point $P_{11}$ is placed on the second curve, so (18) can be written:

$$
V_{11}=P_{11 x}=\left(1-t_{11}\right)^{3} P_{10 x}+3 t_{11}\left(1-t_{11}\right)^{2} P_{11 x}+3 t_{11}^{2}\left(1-t_{11}\right) P_{12 x}+t_{11}^{3} P_{13 x}
$$

Solving the previous equation and keeping only the real solution for $t_{11},(19)$ is also valid:

$$
I_{11}=P_{11 y}=\left(1-t_{11}\right)^{3} P_{10 y}+3 t_{11}\left(1-t_{11}\right)^{2} P_{11 y}+3 t_{11}^{2}\left(1-t_{11}\right) P_{12 y}+t_{11}^{3} P_{13 y}
$$

Finally, the graph also goes through the MPP point $P_{m p}\left(V_{m p}, I_{m p}\right)$, yielding equation (20):

$$
V_{m p}=\left(1-t_{m p}\right)^{3} P_{20 x}+3 t_{m p}\left(1-t_{m p}\right)^{2} P_{21 x}+3 t_{m p}^{2}\left(1-t_{m p}\right) P_{22 x}+t_{m p}^{3} P_{23 x}
$$

Keeping only the real solution for $t_{m p},(21)$ is also valid:

$$
I_{m p}=\left(1-t_{m p}\right)^{3} P_{20 y}+3 t_{m p}\left(1-t_{m p}\right)^{2} P_{21 y}+3 t_{m p}^{2}\left(1-t_{m p}\right) P_{22 y}
$$

The linear system made of equations (17), (19) and (21) give the last three unknown coordinates $P_{12 y}, P_{13 y}$ and $P_{21 y}$. The results are summarized in Table 4 . The application code written for coordinate finding can be found here: http://tess.upt.ro. 
Table 4. The control point coordinates when using three cubic Bézier curves.

\begin{tabular}{ccc}
\hline Point & $\boldsymbol{x}$ coordinate $(\mathrm{V})$ & $\boldsymbol{y}$ coordinate (A) \\
\hline \multicolumn{3}{c}{ First Bézier cubic curve } \\
$P_{00}$ & 0 & 9.207 \\
$P_{01}$ & 0.1165 & 9.206 \\
$P_{02}$ & 0.2330 & 9.204 \\
$P_{03}$ & 0.3495 & 9.202 \\
\multicolumn{3}{c}{ Second Bézier cubic curve } \\
$P_{10}$ & 0.3495 & 9.202 \\
$P_{11}$ & 0.4078 & 9.197 \\
$P_{12}$ & 0.4660 & 9.210 \\
$P_{13}$ & 0.5243 & 9.074 \\
& Third Bézier cubic curve \\
$P_{20}$ & 0.5243 & 9.074 \\
$P_{21}$ & 0.5825 & 8.939 \\
$P_{22}$ & 0.6408 & 8.616 \\
$P_{23}$ & 0.6990 & 0 \\
\hline
\end{tabular}

Figure 9 shows the location of the control points with respect to the I-V characteristic of the PV cell. The control points $P_{00}, P_{01}, P_{02}, P_{03}=P_{10}$ and $P_{11}$ are collinear and with $P_{m p}$, are all being placed on the I-V characteristic.

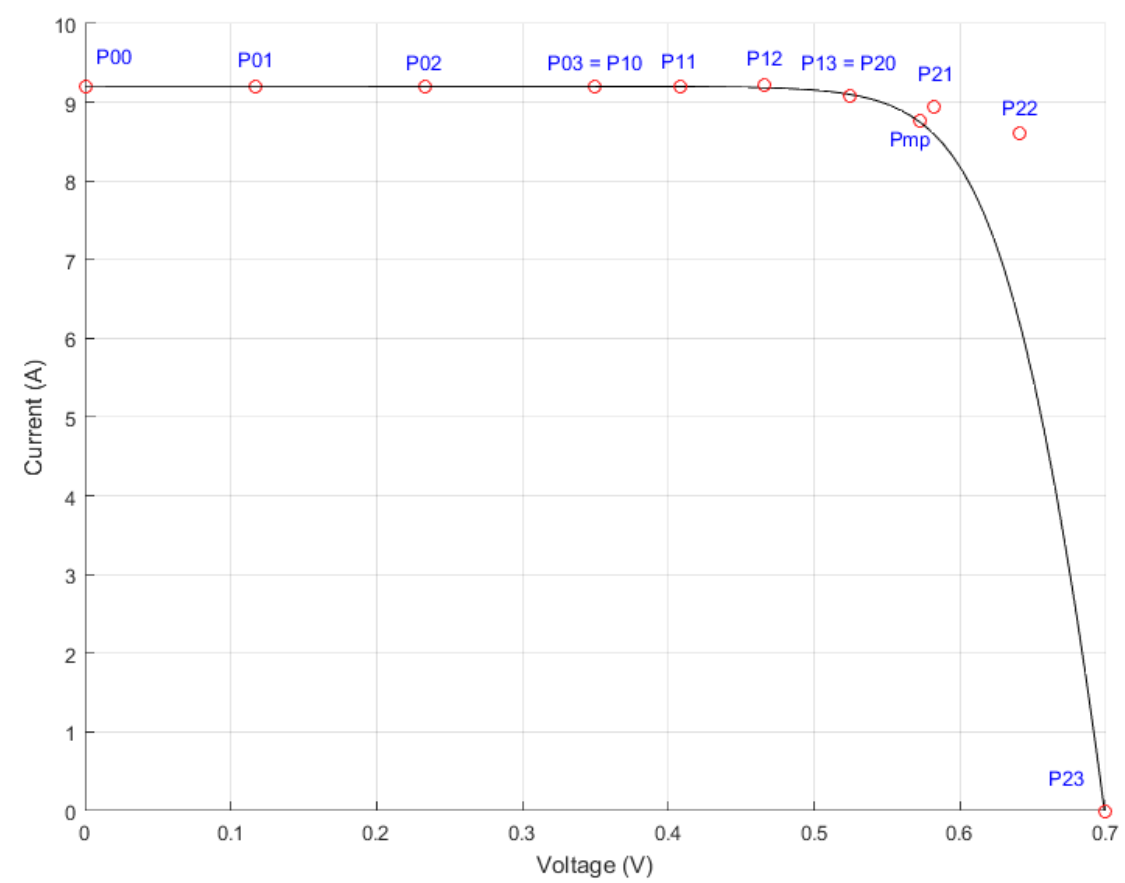

Figure 9. PV cell I-V characteristic (black line, continuous) and the position of the 12 computed control points (red markers).

Figure 10 shows the modeled characteristic (red, green and blue lines) overlapping in most areas with the practical I-V characteristic (black markers). The application code can also be found here: http://tess.upt.ro. 


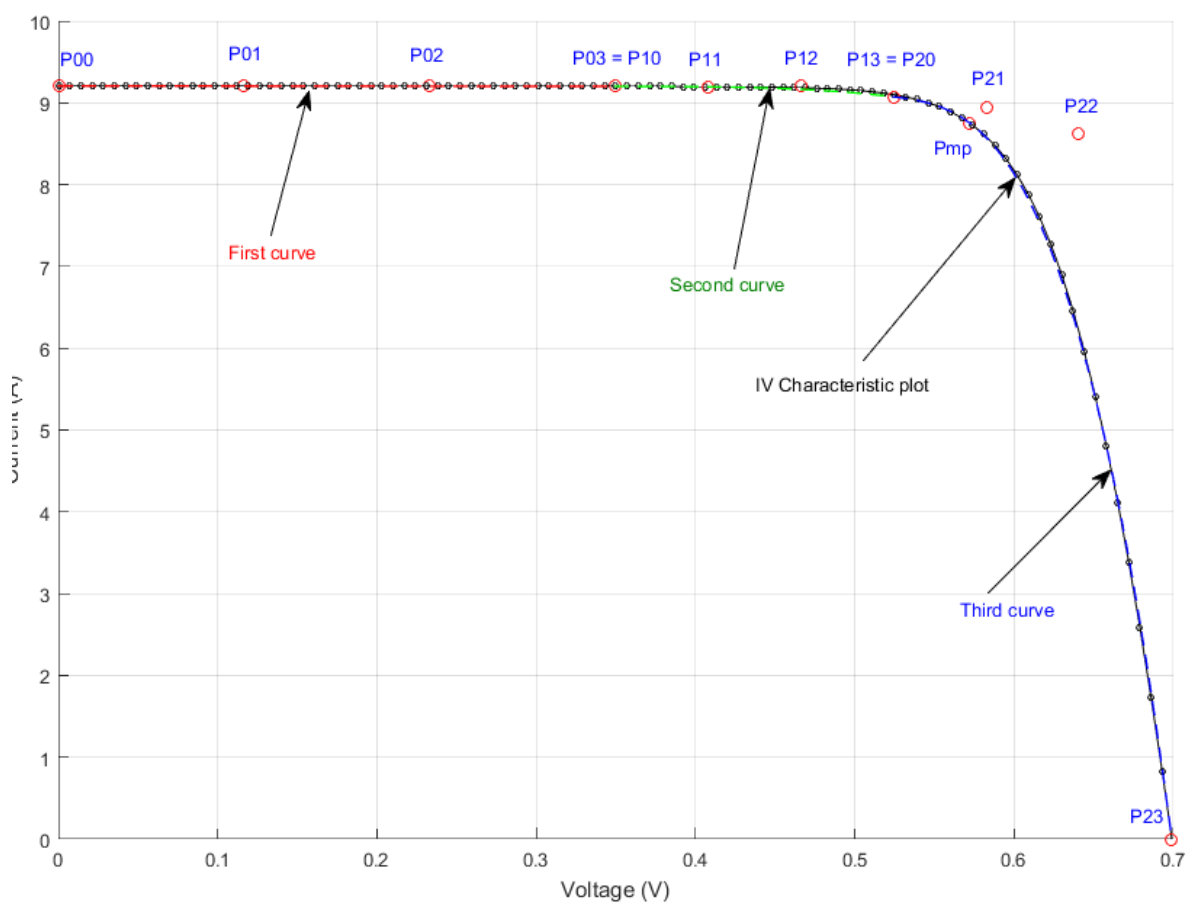

Figure 10. I-V characteristic of a PV cell modeled with three cubic Bézier curves, defined by 12 control points.

The relative error of the Bézier modeled I-V characteristic against the actual data taken from [12] is shown in Figure 11. It must be emphasized that in the $0 \ldots 0.94 V_{o c}$ range, the relative error is below $1 \%$. Above $0.94 V_{o c}$ the absolute error is less than $72 \mathrm{~mA}$, while the reference $I_{s c}=9.207 \mathrm{~A}$.

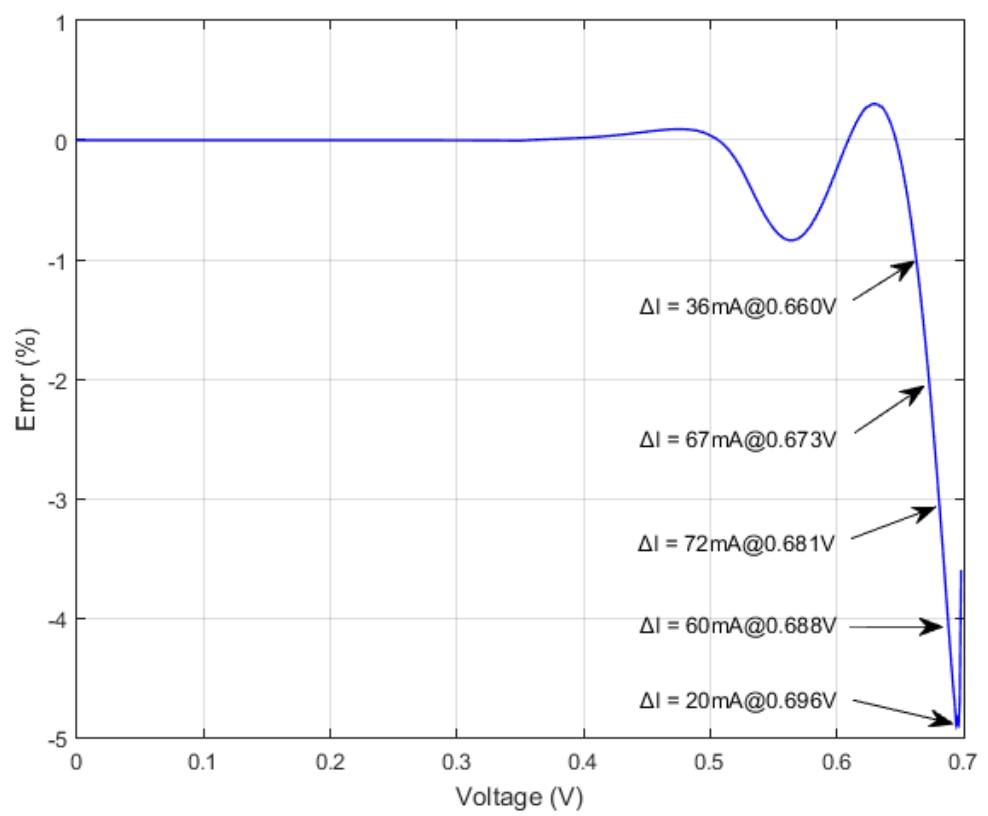

Figure 11. The relative error of our model compared with the actual data. Good performance can be observed in the $0 \ldots 0.5 \mathrm{~V}$ interval and near $V_{m p}$. Higher errors occur near $V_{o c}$ for low output currents.

\subsection{Data fitting using the least squares method}

Data fitting using the least squares method is a standard approach in data analysis [26, 27]. A good overview of curve fitting using Bézier cubic curves in image processing is given by Shao et al. in [28], while Zhao et al. [29] extend this method using a genetic algorithm for parameter optimization 
for Bézier curve fitting. In Section 4.2 we have shown that for the studied PV cell, the best results arise when the $x$ coordinates of the middle end points are set at $0.5 V_{o c}$ and $0.75 V_{o c}$ respectively. A similar conclusion arises if the least squares method is used for the same cell modeling. Running the least squares method for the MSMD290AS-36_EU Monocrystalline PV module proved that the minimum error occurs when the control end points are set again at $0.5 V_{o c}$ and $0.75 V_{o c}$ respectively. Table 5 summarizes the data fitting results for the same PV cell used in sections 4.1 and 4.2, where the results from the two approaches are very close. The graphical representation of the date fitting is given in Figure 12, where just the endpoints are represented.

Table 5. Control point coordinates comparison. On the left, the least squares method is used for computation, on the right the same values as in Table 4 are listed.

\begin{tabular}{ccccc}
\hline & \multicolumn{2}{c}{ Least Squares Method } & \multicolumn{2}{c}{ Proposed Method } \\
\hline Point & $x$ coordinate $(\mathrm{V})$ & $y$ coordinate $(\mathrm{A})$ & $x$ coordinate $(\mathrm{V})$ & $y$ coordinate $(\mathrm{A})$ \\
$P_{00}$ & 0 & First Bézier cubic curve & \\
$P_{01}$ & 0.1165 & 9.207 & 0 & 9.207 \\
$P_{02}$ & 0.2330 & 9.206 & 0.1165 & 9.206 \\
$P_{03}$ & 0.3495 & 9.204 & 0.2330 & 9.204 \\
& \multicolumn{5}{c}{ Second Bézier cubic curve } \\
$P_{10}$ & 0.3495 & 9.202 & 0.3495 & 9.202 \\
$P_{11}$ & 0.4076 & 9.183 & 0.4078 & 9.202 \\
$P_{12}$ & 0.4658 & 9.245 & 0.4660 & 9.197 \\
$P_{13}$ & 0.5239 & 9.103 & 0.5243 & 9.210 \\
& 0.5239 & Third Bézier cubic curve & 9.074 \\
$P_{20}$ & 0.5823 & 9.103 & 0.5243 & 9.074 \\
$P_{21}$ & 0.6406 & 8.9646 & 0.5825 & 8.939 \\
$P_{22}$ & 0.6990 & 8.6724 & 0.6408 & 8.616 \\
$P_{23}$ & 0.004 & 0.6990 & 0 \\
\hline
\end{tabular}

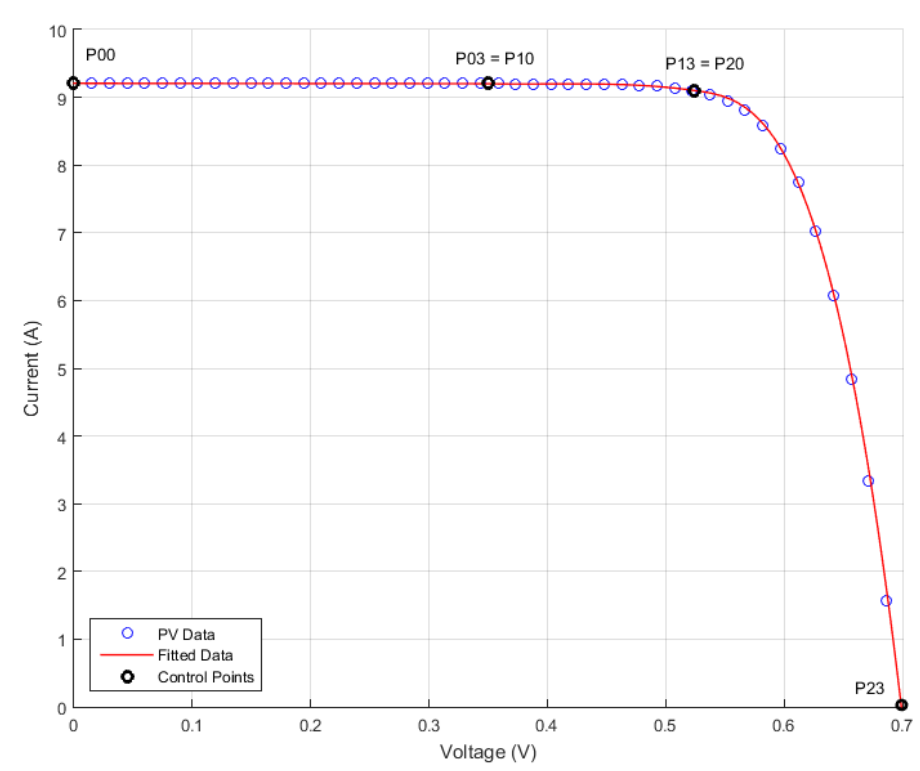

Figure 12. Bézier approximation using the least squares method.

Figure 13 depicts the relative error of the modeled I-V characteristic compared with the actual data taken from our previous work [12]. In the $0 \ldots 0.96 V_{o c}$ range, the relative error is below $2 \%$. Furthermore, above $0.96 V_{o c}$, the absolute error is less than $66 \mathrm{~mA}$, while the reference short circuit current is 9.207A. 


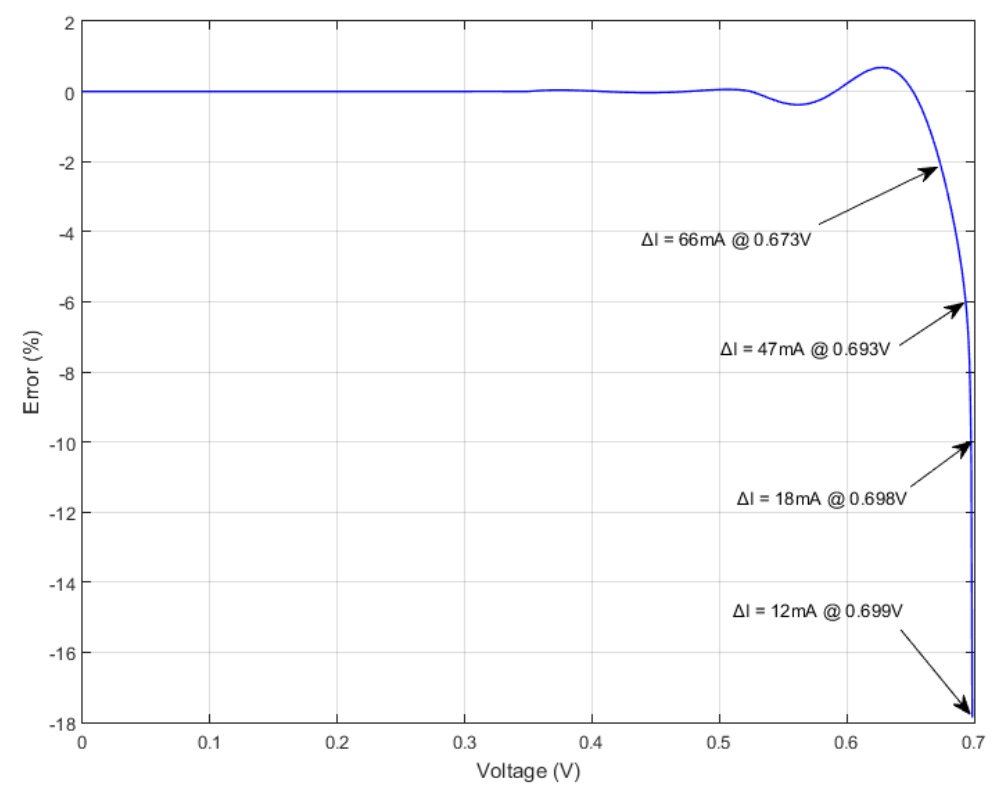

Figure 13. The relative error of the least squares method Bézier based approximation compared with the actual data. The absolute error $\Delta I=I_{\text {Bezier }}-I$ is also indicated.

\subsection{Parameters variation}

In order to further validate the proposed method, in this section we analyze the temperature and irradiance influence for the MSMD290AS-36_EU Monocrystalline PV module. An extensive study of the parameters influence over the PV cell can be found in [12]. It is important to notice that the Bézier approximation is not related to any of these parameters variation, just to the specified points $P_{s c}, P_{m p}, P_{o c}$ and the parasitic resistances $R_{s h 0}$ and $R_{s 0}$ as already stated. The challenge becomes in this case the finding of the new position for the control points and the new values for the parasitic resistances.

Villalva et al. [5] accurately describe the short circuit current variation as in (22):

$$
I_{s c}=\left(\frac{R_{s h}+R_{s}}{R_{s h}} I_{s c, r e f}+k_{I} \Delta T\right) \frac{G}{G_{r e f}} \approx\left(I_{s c, r e f}+k_{I} \Delta T\right) \frac{G}{G_{r e f}}
$$

Ishaque and Salam [9] propose for the $V_{o c, \text { cell }}$ the following variation (23):

$$
V_{o c, \text { cell }}=V_{0 c, \text { cell, ref }}+a \frac{k T}{q} \ln \frac{G}{G_{\text {ref }}}+k_{v} \Delta T
$$

Equation (23) proved to be too conservative in this case, as larger $V_{o c, \text { cell }}$ variations were observed. A better approximation is the empirical law (24):

$$
V_{o c}=29.579+2.1934 \ln G
$$

A possible way for defining $R_{s h}$ behavior is suggested in [12], as in (25) with $k_{R s h}$ estimated as 8 for the best fit.

$$
R_{s h}=R_{s h, r e f}\left(\frac{T_{r e f}}{T}\right)^{k_{R s h}}
$$

For $R_{S}$, a linear variation law (26) is given in [12] with $\alpha_{R S}=-0.01 \mathrm{~K}^{-1}$, again for the best fit:

$$
R_{s}=R_{s, r e f}\left[1+\alpha_{R s}\left(T-T_{r e f}\right)\right]
$$


Figure 14 shows the irradiance influence for the I-V module characteristic, where the approximated data using our proposed method is plotted with solid lines and the experimental data is represented with markers. $I_{s c}, V_{o c}, R_{s h}$ and $R_{s}$ were computed using (22), (24), (25) and (26) respectively.

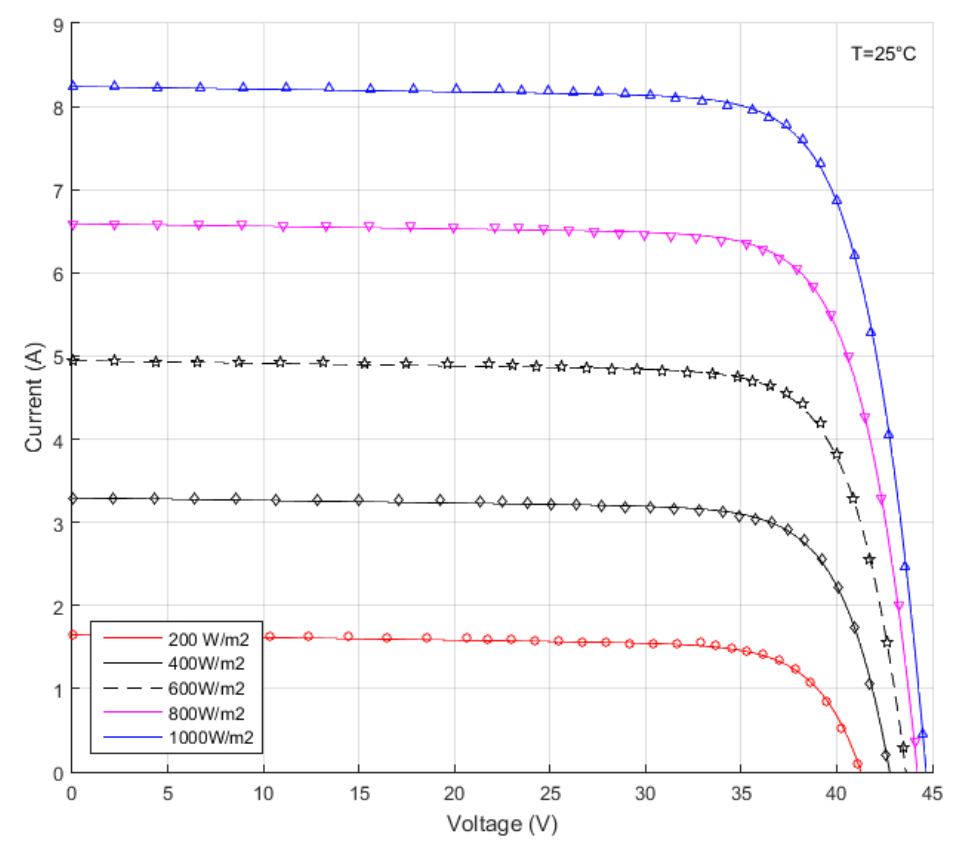

Figure 14. Bézier approximation of the I-V irradiance dependent characteristics for the MSMD290AS36_EU monocrystalline PV module. The lines represent the computed curves, whereas the markers represent the actual data.

The temperature dependent Bézier curves resulted from our algorithm compared with the actual data are introduced in Figure 15. Once again, the results show a very good correlation between the modeled data and the actual data.

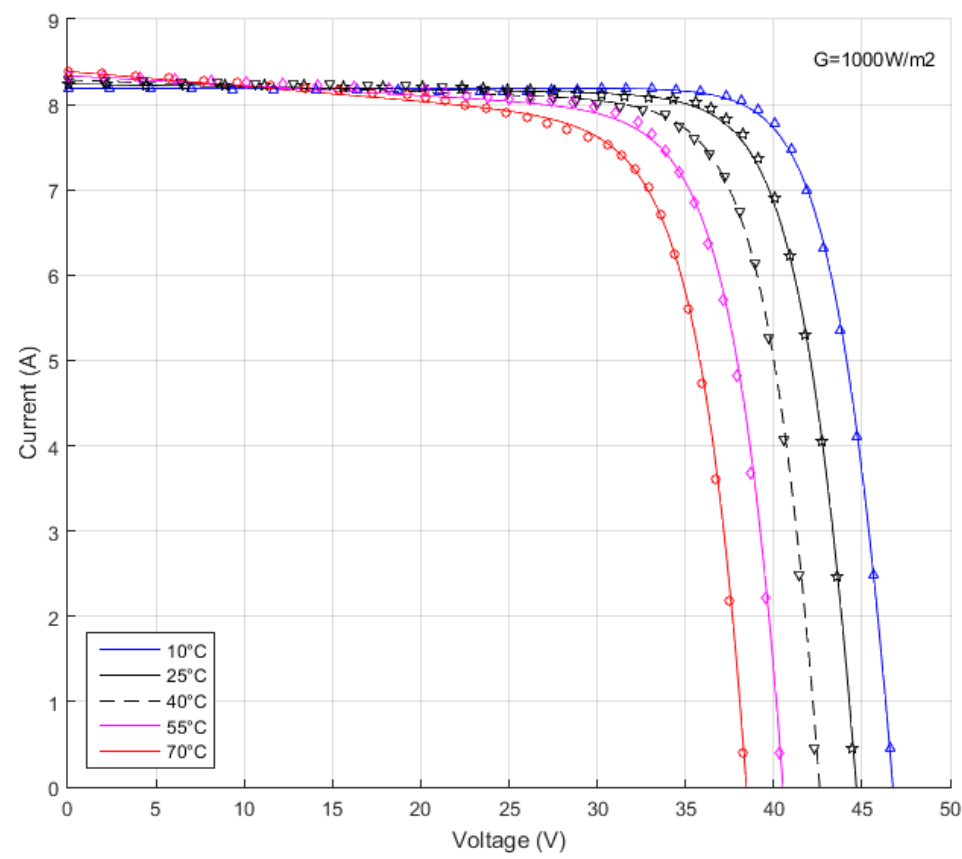

Figure 15. Bézier approximation of the I-V temperature dependent characteristics for the MSMD290AS-36_EU Monocrystalline PV module. The lines represent the computed curves, whereas the markers represent the actual data. 


\subsection{Final validation}

In order to definitely test whether the proposed method is applicable to common PV cells and modules, a selection of 18 cases have been analyzed at reference conditions, based on information found in their technical data [30-44], synthesized in Table 6. The selection includes 3 mono-crystalline PV arrays (1-3), 9 poly-crystalline arrays (4-11 and 13) and 1 poly-crystalline PV cell (12), a thin-film array (14), one Heterojunction with Intrinsic Thin layer (HIT, 15) 2 amorphous silicon glass arrays (with different see-through degrees, respectively 10\% and 30\%, 16 and 17) and eventually an amorphous Silicon cell (18).

Table 6. Datasheet technical data for the analyzed 18 PV cells and modules [30-44].

\begin{tabular}{clcccccccc}
\hline$\#$ & \multicolumn{1}{c}{ PV Type } & Tech & $\boldsymbol{n}_{\boldsymbol{s}}$ & $\begin{array}{c}\boldsymbol{V}_{\boldsymbol{o c}} \\
(\boldsymbol{V})\end{array}$ & $\begin{array}{c}\boldsymbol{V}_{\boldsymbol{m} \boldsymbol{p}} \\
(\boldsymbol{V})\end{array}$ & $\begin{array}{c}\boldsymbol{I}_{\boldsymbol{m} \boldsymbol{p}} \\
(\boldsymbol{A})\end{array}$ & $\begin{array}{c}\boldsymbol{I}_{\boldsymbol{s c}} \\
(\boldsymbol{A})\end{array}$ & $\begin{array}{c}\boldsymbol{k}_{\boldsymbol{V}} \\
(\mathbf{V} / \mathbf{K})\end{array}$ & $\begin{array}{c}\boldsymbol{k}_{\boldsymbol{I}} \\
(\mathbf{A} / \mathbf{K})\end{array}$ \\
\hline 1 & Shell SP-70 & Mono & 36 & 21.4 & 16.5 & 4.24 & 4.7 & -0.076 & 0.002 \\
2 & Isofoton I150 InDach & Mono & 36 & 22.6 & 18.5 & 8.12 & 8.7 & -0.1026 & 0.00365 \\
3 & Bosch M245 3BB & Mono & 60 & 37.8 & 30.11 & 8.14 & 8.72 & -0.11718 & 0.002703 \\
4 & MSP300AS-36.EU & Poly & 72 & 44.48 & 37.42 & 8.02 & 8.58 & -0.14678 & 0.003432 \\
5 & Kyocera KG200GT & Poly & 54 & 32.9 & 26.3 & 7.61 & 8.21 & -0.123 & 0.00318 \\
6 & Kyocera KC85T & Poly & 36 & 21.7 & 17.4 & 5.02 & 5.34 & -0.0821 & 0.00212 \\
7 & Kyocera KD135SX_UPU & Poly & 36 & 22.1 & 17.7 & 7.63 & 8.37 & -0.08 & 0.00502 \\
8 & Kyocera KD245GH-4FB2 & Poly & 60 & 36.9 & 29.8 & 8.23 & 8.91 & -0.133 & 0.00535 \\
9 & Sharp ND-224uC1 & Poly & 60 & 36.6 & 29.3 & 7.66 & 8.33 & -0.13176 & 0.004415 \\
10 & Shell S36 & Poly & 36 & 21.4 & 16.5 & 2.18 & 2.3 & -0.076 & 0.001 \\
11 & Solarex MSX-60 & Poly & 36 & 21.1 & 17.1 & 3.5 & 3.8 & -0.08 & 0.003 \\
12 & Solarex MSX-60 - cell & Poly & 1 & 0.586 & 0.475 & & & -0.00222 & \\
13 & Amerisolar AS-6P 300W & Poly & 72 & 44.7 & 36.7 & 8.19 & 8.68 & -0.14751 & $4.86 \mathrm{E}-03$ \\
14 & Shell ST40 & Thin-Film & 36 & 23.3 & 16.6 & 2.41 & 2.68 & -0.1 & 0.00035 \\
15 & Sanyo HIT-240 HDE4 & HIT & 60 & 43.6 & 35.5 & 6.77 & 7.37 & -0.109 & 0.00221 \\
16 & Onyx 1200x600 Ref10 & & & & & 0.9 & 1.11 & -0.0893 & 0.000999 \\
17 & Onyx 1200x600 Ref30 & aSi glass & 72 & 47 & 32 & 0.63 & 0.74 & & 0.000666 \\
18 & 6.5Wp L Cel & aSi cell & 1 & 2.2 & 1.6 & 4.09 & 5.1 & -0.00836 & 0.00612 \\
\hline
\end{tabular}

Using the Villalva algorithm [5], the main parameters were computed and listed in Table 7. For the last 3 cases, due to different technology, interesting values for the diode ideality factor $a$ occur.

Table 7. Computed values for main parameters of the analyzed PV cells and modules.

\begin{tabular}{cccccccc}
\hline$\#$ & $\boldsymbol{R}_{\boldsymbol{s}}(\boldsymbol{\Omega})$ & $\boldsymbol{R}_{\boldsymbol{s h}}(\boldsymbol{\Omega})$ & $\boldsymbol{I}_{\mathbf{0}}(\mathbf{A})$ & $\boldsymbol{I}_{\boldsymbol{p} \boldsymbol{v}}(\mathbf{A})$ & $\boldsymbol{a}$ & $\boldsymbol{R}_{\boldsymbol{s} \mathbf{0}}(\boldsymbol{\Omega})$ & $\boldsymbol{R}_{\boldsymbol{s h} \mathbf{0}}(\boldsymbol{\Omega})$ \\
\hline 1 & 0.506 & 74.30 & $6.57 \mathrm{E}-10$ & 4.732 & 1.022 & 0.691 & 95.27 \\
2 & 0.109 & 284.83 & $2.17 \mathrm{E}-08$ & 8.703 & 1.234 & 0.233 & 304.09 \\
3 & 0.378 & 220.45 & $2.55 \mathrm{E}-10$ & 8.735 & 1.012 & 0.535 & 266.54 \\
4 & 0.142 & 192.59 & $5.23 \mathrm{E}-10$ & 8.586 & 1.023 & 0.372 & 202.92 \\
5 & 0.308 & 193.05 & $2.15 \mathrm{E}-09$ & 8.223 & 1.076 & 0.463 & 225.66 \\
6 & 0.277 & 439.46 & $1.63 \mathrm{e}-09$ & 5.343 & 1.071 & 0.437 & 502.34 \\
7 & 0.19 & 51.83 & $1.51 \mathrm{E}-09$ & 8.401 & 1.067 & 0.3161 & 60.474 \\
8 & 0.28 & 140.26 & $1.56 \mathrm{E}-09$ & 8.928 & 1.067 & 0.438 & 161.66 \\
9 & 0.317 & 108.98 & $1.41 \mathrm{E}-09$ & 8.354 & 1.057 & 0.501 & 127.07 \\
10 & 0.968 & $1.24 \mathrm{E}+06$ & $3.41 \mathrm{E}-10$ & 2.3 & 1.022 & 1.332 & 151053 \\
11 & 0.316 & 146.08 & $1.22 \mathrm{E}-09$ & 3.808 & 1.045 & 0.557 & 164.26 \\
12 & 0.009 & 4.19 & $1.21 \mathrm{E}-09$ & 3.809 & 1.045 & 0.016 & 4.788 \\
13 & 0.264 & 405.65 & $5.50 \mathrm{E}-10$ & 8.686 & 1.030 & 0.458 & 450.79 \\
14 & 1.555 & 210.33 & $3.30 \mathrm{E}-09$ & 2.7 & 1.23 & 2.168 & 300.48 \\
15 & 0.437 & 117.72 & $1.75 \mathrm{E}-11$ & 7.397 & 1.058 & 0.637 & 138.19 \\
16 & 11.57 & 186.22 & $1.21 \mathrm{E}-13$ & 1.179 & 0.856 & 13.60 & 204.51 \\
17 & 16.639 & 418.79 & $8.60 \mathrm{E}-14$ & 0.769 & 0.856 & 19.50 & 459.43 \\
18 & 0.079 & 2.06 & $1.52 \mathrm{E}-09$ & 5.296 & 3.938 & 0.103 & 2.13 \\
\hline
\end{tabular}


Table 8 lists the control points computed for Bézier curve fitting, where in all cases the control end points are set at $0.5 V_{o c}$ and $0.75 V_{o c}$ respectively. Just two $x$ coordinates are presented, as the others are evenly spaced and can be easily computed. Selected plots of the PV devices are presented in Figure 16.

Table 8. Control points coordinates of the analyzed PV cells and modules.

\begin{tabular}{cccccccccccc}
\hline \multicolumn{1}{c}{$\boldsymbol{x}$ coord. (V) } & \multicolumn{10}{c}{$\boldsymbol{y}$ coordinates (A) } \\
\hline$\#$ & 03 & 13 & 00 & 01 & 02 & 03 & 11 & 12 & 13 & 21 & 22 \\
\hline 1 & 10.628 & 15.931 & 4.732 & 4.684 & 4.637 & 4.588 & 4.538 & 4.606 & 4.360 & 4.212 & 2.575 \\
2 & 11.295 & 16.930 & 8.703 & 8.690 & 8.678 & 8.663 & 8.635 & 8.696 & 8.508 & 8.210 & 8.125 \\
3 & 18.870 & 28.285 & 8.735 & 8.706 & 8.678 & 8.649 & 8.604 & 8.697 & 8.453 & 8.529 & 5.997 \\
4 & 22.224 & 33.312 & 8.586 & 8.547 & 8.509 & 8.470 & 8.443 & 8.453 & 8.370 & 7.684 & 9.991 \\
5 & 16.425 & 24.620 & 8.223 & 8.194 & 8.167 & 8.137 & 8.094 & 8.178 & 7.930 & 7.909 & 5.930 \\
6 & 10.845 & 16.256 & 5.343 & 5.335 & 5.327 & 5.318 & 5.298 & 5.350 & 5.212 & 5.200 & 4.168 \\
7 & 10.975 & 16.451 & 8.401 & 8.3301 & 8.260 & 8.189 & 8.128 & 8.178 & 7.946 & 7.918 & 6.273 \\
8 & 18.415 & 27.603 & 8.928 & 8.883 & 8.841 & 8.796 & 8.749 & 8.812 & 8.595 & 8.581 & 7.029 \\
9 & 18.228 & 27.362 & 8.354 & 8.298 & 8.243 & 8.187 & 8.133 & 8.191 & 7.967 & 7.954 & 6.288 \\
10 & 10.940 & 16.399 & 2.300 & 2.300 & 2.300 & 2.299 & 2.287 & 2.331 & 2.226 & 2.180 & 1.367 \\
11 & 10.527 & 15.779 & 3.808 & 3.784 & 3.760 & 3.736 & 3.715 & 3.733 & 3.649 & 3.599 & 3.241 \\
12 & 0.293 & 0.438 & 3.809 & 3.786 & 3.763 & 3.739 & 3.718 & 3.738 & 3.652 & 3.608 & 3.204 \\
13 & 22.336 & 33.479 & 8.686 & 8.667 & 8.649 & 8.630 & 8.606 & 8.650 & 8.525 & 8.411 & 8.209 \\
14 & 11.565 & 17.335 & 2.700 & 2.680 & 2.666 & 2.642 & 2.606 & 2.669 & 2.275 & 1.868 & 0.969 \\
15 & 21.720 & 32.557 & 7.397 & 7.336 & 7.274 & 7.213 & 7.168 & 7.185 & 7.063 & 7.200 & 5.950 \\
16 & 23.500 & 35.225 & 1.110 & 1.0717 & 1.0343 & 0.995 & 0.971 & 0.978 & 0.775 & 0.578 & 0.289 \\
17 & 23.500 & 35.225 & 0.740 & 0.723 & 0.707 & 0.689 & 0.677 & 0.686 & 0.542 & 0.403 & 0.201 \\
18 & 1.100 & 1.649 & 5.100 & 4.928 & 4.760 & 4.584 & 4.456 & 4.506 & 3.949 & 3.372 & 1.786 \\
\hline
\end{tabular}

In the second column of Table 9, the average of the current $(I)$ relative error is displayed in order to evaluate the fit quality. Maximum current error (absolute and relative values) is listed in each case with the coordinates where it appears. The maximum power point is also investigated as an absolute and relative error and finally the computed value is listed. The current $(I)$ relative error is below $1.18 \%$ in all cases, and the $P_{m p}$ relative error is even better (lower than $1 \%$ in all cases).

Table 9. Computed errors for the analyzed PV cells and modules.

\begin{tabular}{|c|c|c|c|c|c|c|c|c|}
\hline \multirow{3}{*}{ \# } & \multicolumn{5}{|c|}{ Current (I) Error } & \multicolumn{3}{|c|}{ Max. Power $\left(\boldsymbol{P}_{m p}\right)$ Error } \\
\hline & \multirow{2}{*}{$\begin{array}{c}\text { Avg.Rel. } \\
(\%)\end{array}$} & \multicolumn{2}{|c|}{ Coordinates } & \multirow{2}{*}{$\begin{array}{l}\text { Abs. } \\
(\mathrm{mA})\end{array}$} & \multirow{2}{*}{$\begin{array}{l}\text { Rel. } \\
(\%)\end{array}$} & \multirow{2}{*}{$\begin{array}{l}\text { Abs. } \\
(W)\end{array}$} & \multirow{2}{*}{$\begin{array}{l}\text { Rel. } \\
(\%)\end{array}$} & \multirow{2}{*}{$\begin{array}{c}\text { Comp. } \\
\text { (W) }\end{array}$} \\
\hline & & $V(\mathrm{~V})$ & $I(\mathrm{~A})$ & & & & & \\
\hline 1 & -0.11 & 18.423 & 3.247 & 16.63 & 0.52 & -0.363 & -0.52 & 70.32 \\
\hline 2 & -0.08 & 20.398 & 6.325 & 21.97 & 0.35 & -0.246 & -0.16 & 150.47 \\
\hline 3 & -0.21 & 32.952 & 6.615 & 59.85 & 0.90 & -1.80 & -0.74 & 246.90 \\
\hline 4 & 0.10 & 34.638 & 8.319 & 92.81 & 1.12 & -1.99 & -0.66 & 302.10 \\
\hline 5 & -0.19 & 28.788 & 6.183 & 50.70 & 0.82 & -1.223 & -0.61 & 201.37 \\
\hline 6 & -0.20 & 19.077 & 4.105 & 33.65 & 0.82 & -0.481 & -0.55 & 87.83 \\
\hline 7 & -0.20 & 19.306 & 6.225 & 52.58 & 0.84 & -0.227 & -0.17 & 135.28 \\
\hline 8 & -0.20 & 32.432 & 6.801 & 57.57 & 0.85 & -1.242 & -0.51 & 246.50 \\
\hline 9 & -0.20 & 32.103 & 6.248 & 53.40 & 0.86 & -1.308 & -0.58 & 225.75 \\
\hline 10 & -0.13 & 18.548 & 1.675 & 9.200 & 0.55 & -0.240 & -0.67 & 36.21 \\
\hline 11 & -0.17 & 18.697 & 2.867 & 19.97 & 0.70 & -0.215 & -0.36 & 60.07 \\
\hline 12 & -0.17 & 0.519 & 2.872 & 20.60 & 0.72 & -0.006 & -0.38 & 1.669 \\
\hline 13 & -0.17 & 39.909 & 6.788 & 47.91 & 0.71 & -0.914 & -0.30 & 301.49 \\
\hline 14 & 0.03 & 12.255 & 2.635 & 3.32 & 0.13 & 0.093 & 0.23 & 39.91 \\
\hline 15 & -0.27 & 38.253 & 5.730 & 67.47 & 1.18 & -1.253 & -0.52 & 241.59 \\
\hline 16 & 0.04 & 30.966 & 0.925 & 0.94 & 0.10 & 0.015 & 0.05 & 28.79 \\
\hline 17 & 0.04 & 30.816 & 0.650 & 0.79 & 0.12 & 0.010 & 0.05 & 20.15 \\
\hline 18 & 0.014 & 1.578 & 4.142 & 7.09 & 0.17 & 0.01 & 0.16 & 6.53 \\
\hline
\end{tabular}

Avg.Rel. $=$ The average of the relative rror, Abs. $=$ absolute error, Rel. $=$ relative error, Comp. $=$ computed value 

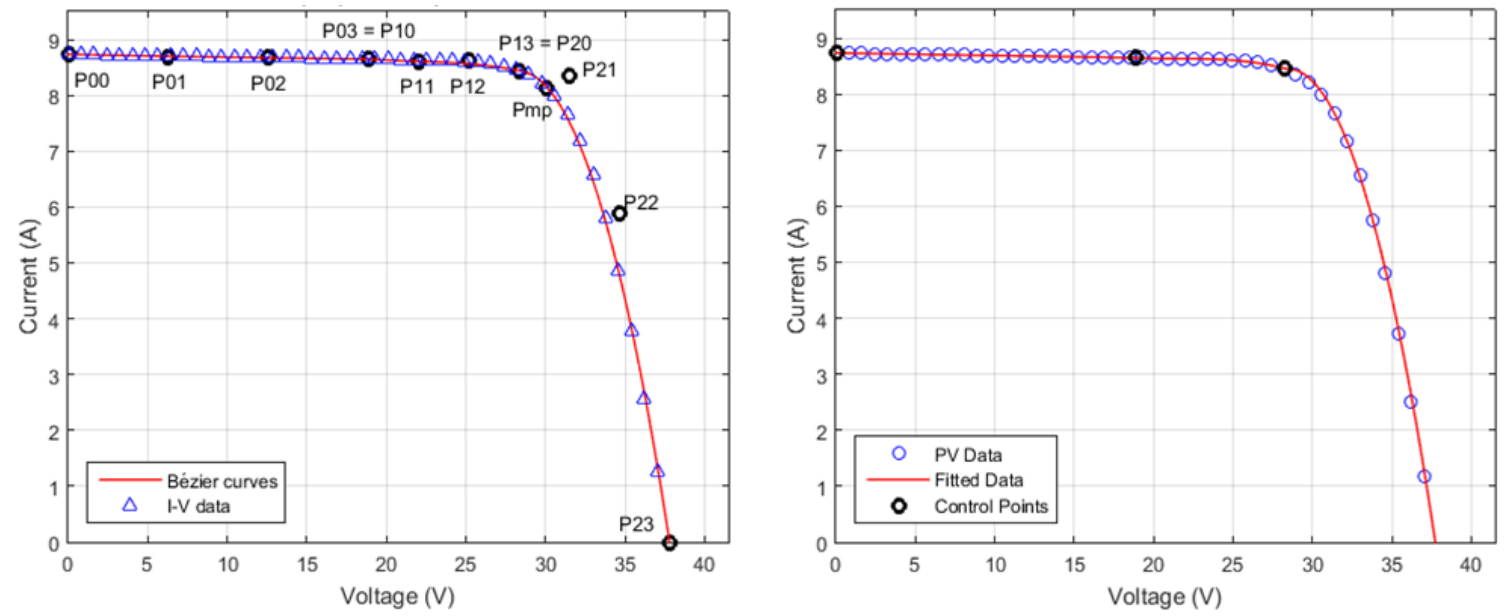

(a) \#3 Bosch M245 3BB
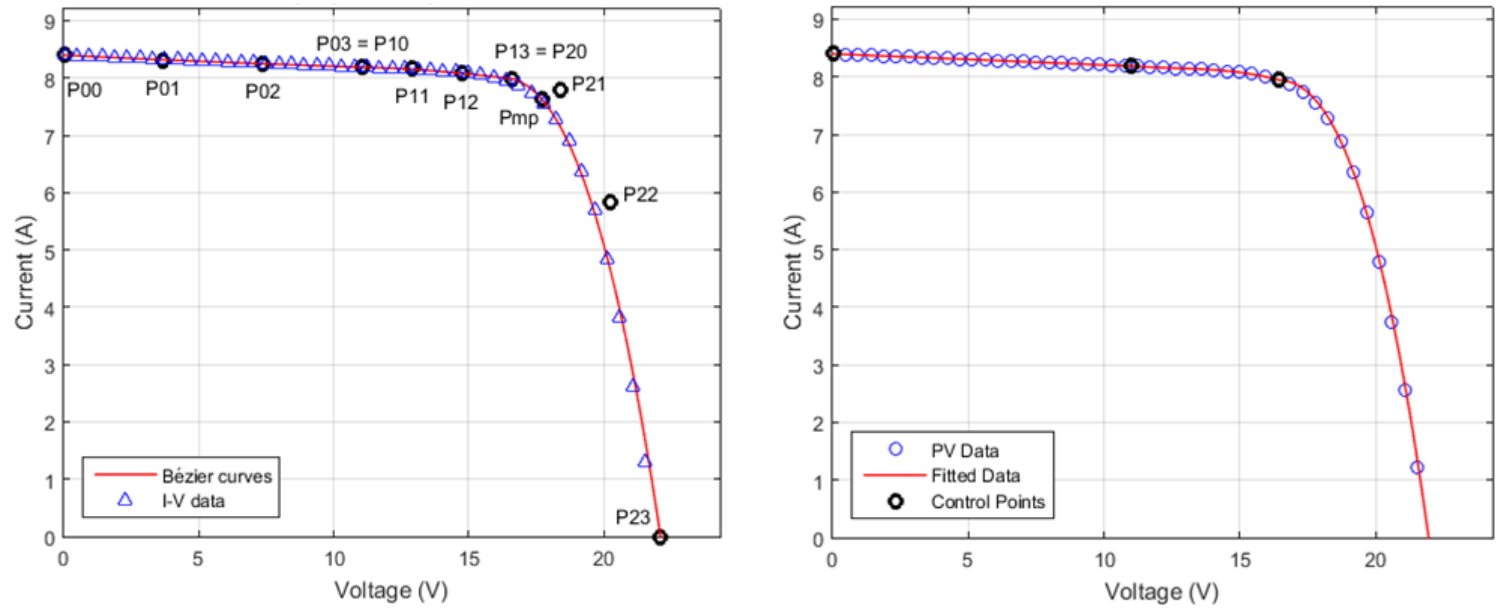

(b) \#7 Kyocera KD135SX_UPU
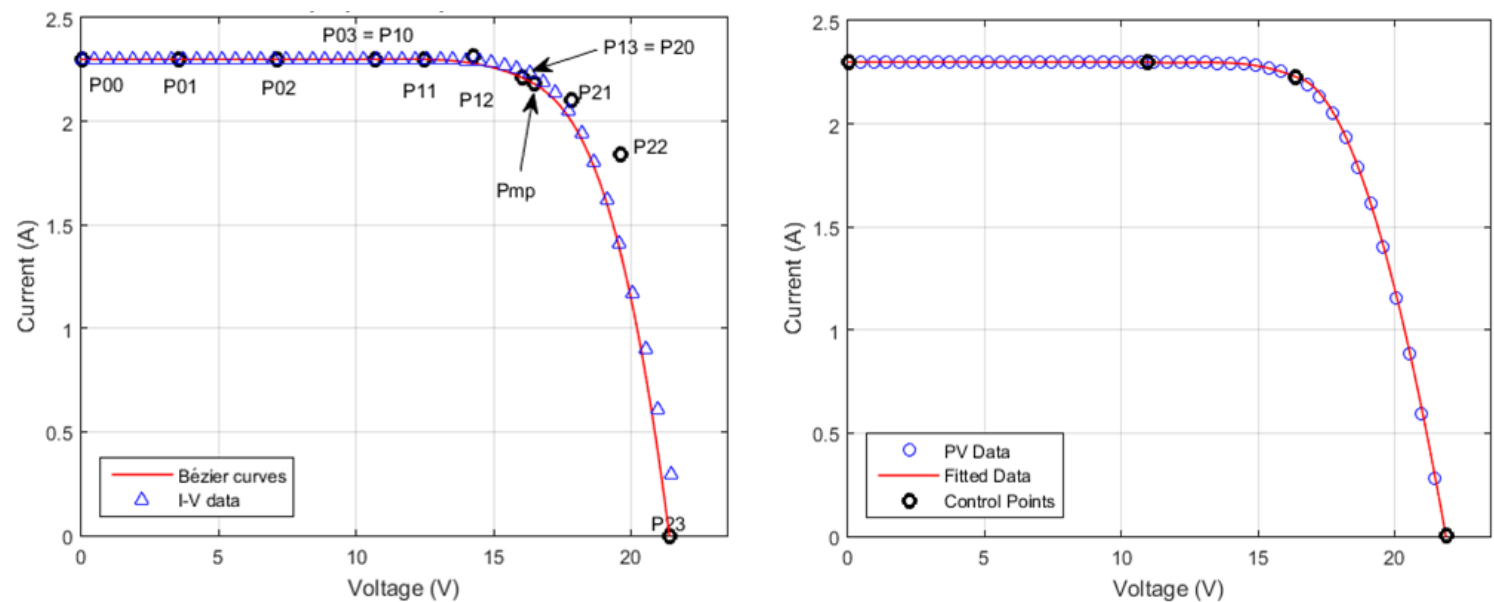

(c) \#10 Shell S36

Figure 16. Cont. 

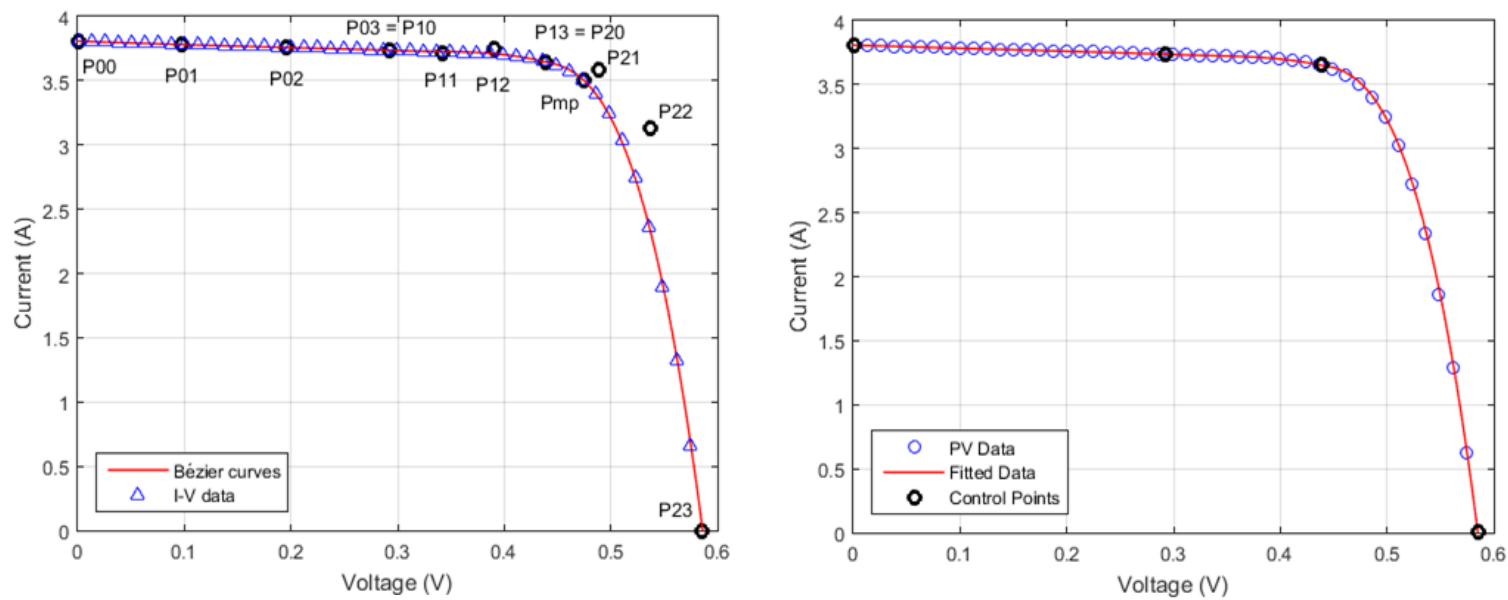

(d) \#12 MSX-60 Single Cell
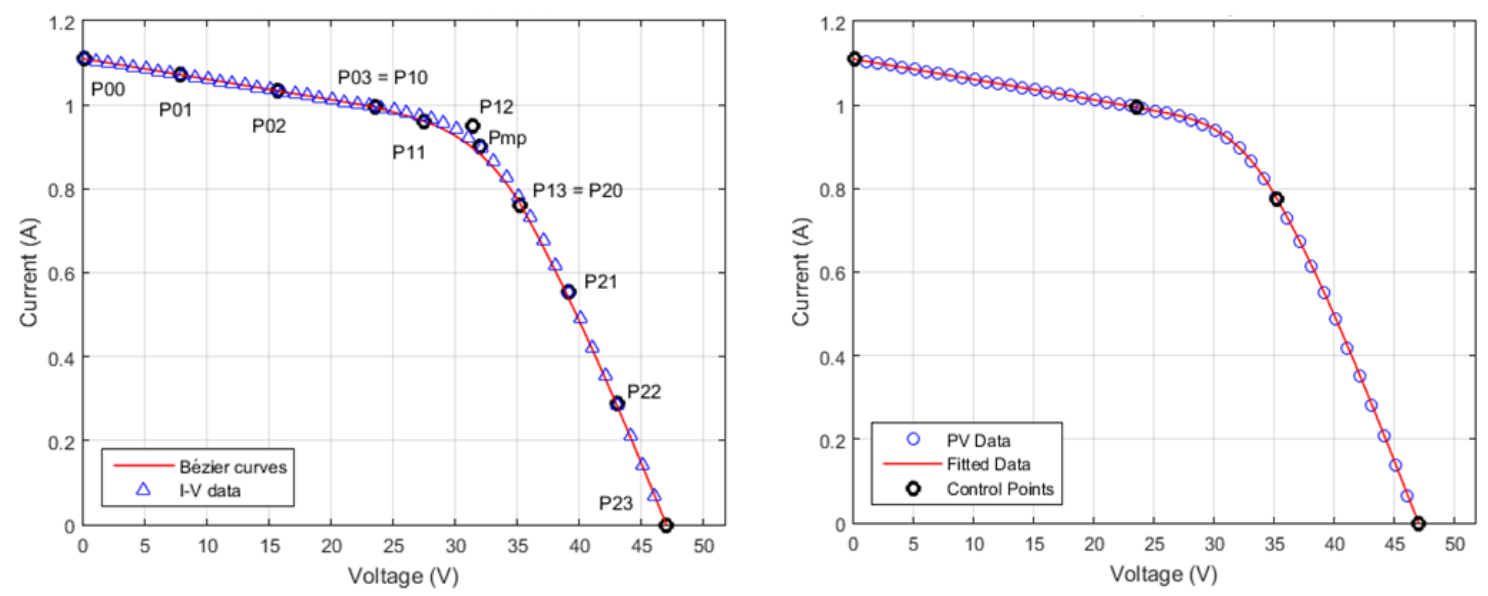

(e) \#16 Onyx Ref 10
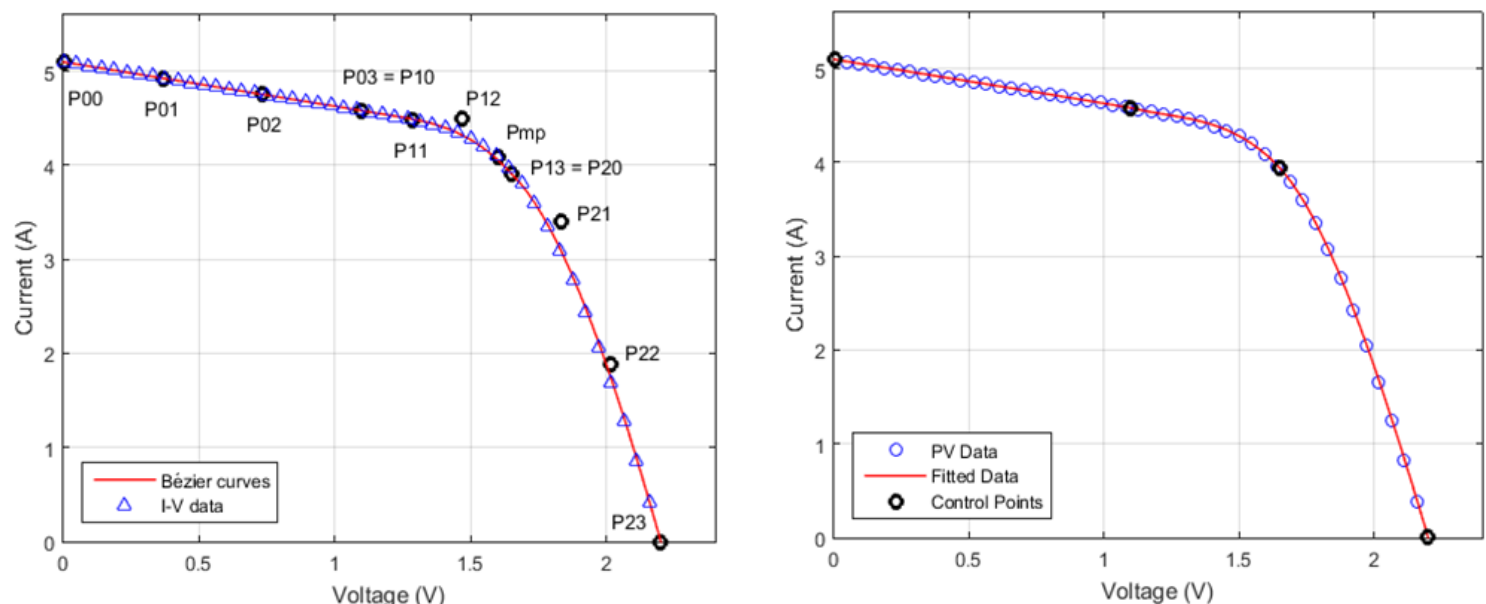

(f) \#18 6.5Wp L Cell

Figure 16. Bézier approximation of the I-V curves using the proposed method (left) and the least squares method (right). The lines represent the computed curves, whereas the markers represent the actual data. Control point are represented with black dots. (a) Bosch M245 3BB Mono-Crystalline PV module; (b) Kyocera KD135SX_UPU Poly-Crystalline PV module; (c) Shell S36 Poly-Crystalline PV module; (d) Solarex MSX-60 Poly-Crystalline PV Cell; (e) Onyx Ref 10 amorphous Silicon PV Glass module; (f) $6.5 \mathrm{Wp}$ L amorphous Silicon PV Cell. 


\section{Discussion}

In all studied cases, the $x$ coordinates can be evenly spaced. Both for the PV cells and for the PV modules, the first Bézier cubic curve was very close to a straight line and ended at $x_{03}=0.5 V_{o c}$, while the middle curve ended at $x_{13}=0.75 V_{o c}$. The relative error is less than or equal to $1.18 \%$ for all the studied PV devices.

The differences between the results obtained with the proposed method and the least squares method are negligible (less than $1 \%$ for all coordinates). $R_{s}$ and $R_{s h}$ can be easily derived from the manufacturer's datasheet, using for example the method proposed by Vilallva et al. [5]. In most cases $R_{\text {sh }}$ is close to $R_{\text {sho }}$ (Table 7). Larger differences occur for the series parasitic resistance: for the same PV cell. For different irradiances and temperatures, the section 4.4 provides all the necessary formulae.

In most cases $V_{m p}>P_{13 x}$. The method was also valid for Onyx Ref 10, Onyx Ref 30 and 6.5Wp L Cell, where the previous relation was not satisfied.

In relation with the Maximum Power Point Tracking (MPPT), it must be emphasized that the Bézier curves are inherently smooth. This reduces the risk for the algorithm to get stuck in some false area/minimum of the curve. Furthermore, the generation of the Bézier curves being so easy, MPPT simulation can be further simplified.

\section{Conclusions}

A novel method for modeling a PV cell or a PV module I-V characteristic has been introduced. To the best of our knowledge, Bézier curves were not used to model the I-V characteristic of PV devices before. The method proved good accuracy and was validated both in the case of a single PV cell and in the case of a whole PV module, for different technologies and manufacturers. The method was also used in the case of varying irradiance and temperature. The proposed method can be used for implementing hardware solar array simulators, for teaching or remote study. It is far more easy to use the proposed method to find the I-V characteristic of a PV cell or module when compared with solving the exponential equations associated with the single or double diode model largely used today. A common microcontroller can compute the points on the I-V curve with a minimum of resources, inherently increasing the computing speed and the response of the system.

The advantage of our method relies in the ease of I-V characteristic generation: if we exclude $V_{o c}$ and $I_{s c}$, only 10 different values $\left(P_{23 x}=V_{o c}, P_{00 y}=I_{s c}, P_{01 y}, P_{02 y}, P_{03 y}, P_{11 y}, P_{12 y}, P_{13 y}, P_{21 y}, P_{22 y}\right)$ have to be stored - SAS manufacturers usually use 1024 or more double points to accurately define the I-V characteristic. Alternate use is for any graphical plot of the I-V (and subsequently P-V) curves. Furthermore, little knowledge of the device itself is required, as only common data from the datasheet is needed.

Acknowledgments: This work was supported by both the Romanian National Authority for Scientific Research and Innovation, CNCS/CCCDI-UEFISCDI within PNCDI III, project number PN-III-P2-2.1-PED-2016-0074 and by Politehnica University Timisoara, according to the Administration Board research policy.

Author Contributions: Both authors have contributed to this research. Aurel Gontean conceived and designed the study and carried out the simulations. Roland Szabo analyzed the data. Aurel Gontean wrote the paper and reviewed the manuscript. Both authors read and approved the manuscript.

Conflicts of Interest: The authors declare no conflict of interest.

\section{Nomenclature}

Main Symbols
$a$
$G$
$G_{r e f}$
$I$
$I_{m p}$

Main Symbols
Diode ideality factor

Actual irradiance

Reference irradiance, $1000 \mathrm{~W} / \mathrm{m}^{2}$

Output current

Output current at maximum power point 


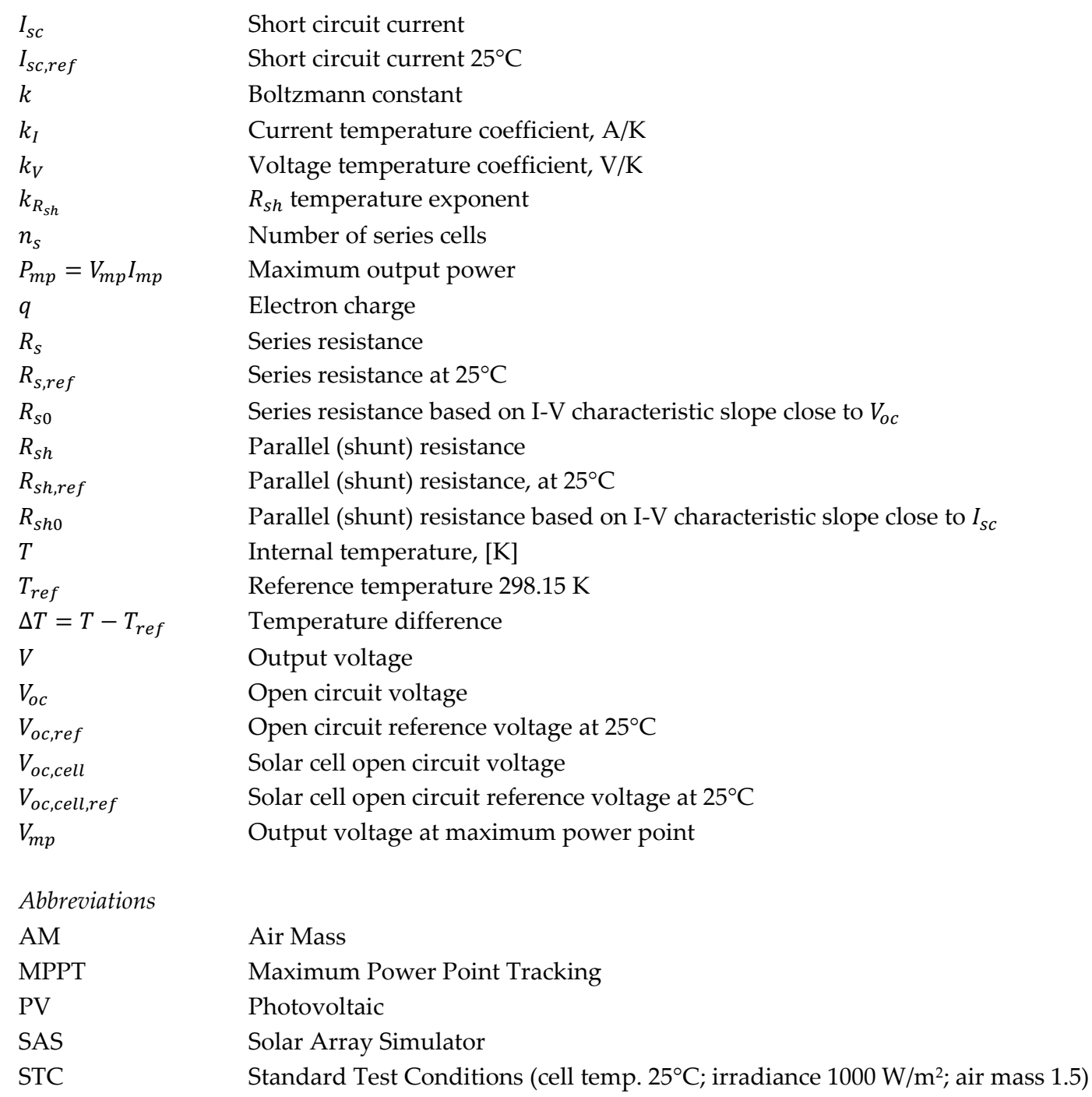

Greek Symbols

$\alpha_{R s}$

Series resistance temperature coefficient (linear law)

\section{References}

1. 4Q 2017 Frontier Power Market Outlook, https://about.bnef.com/blog/4q-2017-frontier-power-marketoutlook/ (accessed on 3 January 2018).

2. Solar PV 2018, https://www.pv-magazine.com/2017/12/01/solar-pv-2018-installs-of-111-gw-a-polysiliconfactory-boom-and-0-30w-for-modules-2/ (accessed on 3 January 2018).

3. Phang, J.C.H.; Chan, D.S.H.; Phillips, J.R. Accurate Analytical Method For The Extraction Of Solar Cell Model Parameters, Electron Lett 1984, 20(10), pp. 406 - 408, DOI: 10.1049/el:19840281.

4. Garrido-Alzar, C.L. Algorithm for extraction of solar cell parameters from I-V curve using double exponential mode, Renew Energy 1997, 10 (2-3), pp. 125-128, https://doi.org/10.1016/0960-1481(96)00049-3.

5. Villalva, M.G.; Gazoli, J.R.; Filho, E.R. Comprehensive Approach to Modeling and Simulation of Photovoltaic Arrays, IEEE Trans. Power Electr. 2009, 24, pp. 1198-1208.

6. Babu, B.C.; Gurjar, S. A novel simplified two-diode model of photovoltaic (PV) module, IEEE J Photovolt 2014, 4(4), 2014, pp. 1156-1161, DOI: 10.1109/JPHOTOV.2014.2316371.

7. Cubas, J.; Pindado, S.; de Manuel, C. Explicit Expressions for Solar Panel Equivalent Circuit Parameters Based on Analytical Formulation and the Lambert W-Function, Energies 2014, 7, pp. 4098-4115.

8. Chander, S.; Purohit, A.; Sharma, A. Nehra, S.P.; Dhaka, M.S., A study on photovoltaic parameters of monocrystalline silicon solar cell with cell temperature, Energy Rep. 2015, 1, pp. 104-109. 
9. Ishaque, K.; Salam, Z. An improved modeling method to determine the model parameters of photovoltaic (PV) modules using differential evolution (DE), Sol Energy 2011, 85(9), pp. 2349 - 2359, DOI: 10.1016/j.solener.2011.06.025.

10. Franzitta, V.; Orioli, A.; Di Gangi, A. Assessment of the Usability and Accuracy of the Simplified OneDiode Models for Photovoltaic Modules, Energies 2016, 9, 1019, DOI:10.3390/en9121019.

11. Franzitta, V.; Orioli, A.; Gangi, A.D. Assessment of the Usability and Accuracy of Two-Diode Models for Photovoltaic Modules, Energies 2017, 10, 564, DOI:10.3390/en10040564.

12. Gontean, A.; Lica, S.; Bularka, S.; Szabo, R.; Lascu, D. A Novel High Accuracy PV Cell Model Including Self Heating and Parameter Variation, Energies 2018, 11, 36, doi:10.3390/en11010036.

13. Cuce, E.; Cuce P.M.; Karakas I.H.; Bali, T. An accurate model for photovoltaic (PV) modules to determine electrical characteristics and thermodynamic performance parameters, Energ Convers Manage 2017 146, pp. 205-216, https://doi.org/10.1016/j.enconman.2017.05.022.

14. Farin, G. A History of Curves and Surfaces in CAGD, in Handbook of Computer Aided Geometric Design; Farin, G.E.; Hoschek, J., Kim, M.S. Eds.; Elsevier, Amsterdam, The Netherlands, 2002; pp. 1-22, ISBN 978-0-44451104-1, https://doi.org/10.1016/B978-0-444-51104-1.50035-6.

15. Farin, G. Curves and Surfaces for CAGD. A Practical Guide, 5th Edition, Academic Press, San Francisco, CA, USA, 2002, pp. 81 - 95, ISBN: 1-55860-737-4, https://doi.org/10.1016/B978-1-55860-737-8.50032-6.

16. Mortenson, M.E. Geometric modeling, $3^{\text {rd }}$ Edition, Industrial Press, South Norwalk CT, USA 2006, ISBN 9780-831-13298-9.

17. Farin, G. Shape Representation, in Wiley Encyclopedia of Electrical and Electronics Engineering, Published Online: 13 Jul 2007, http://onlinelibrary.wiley.com/doi/10.1002/047134608X.W7525.pub2/full, ISBN: 978-0471-34608-1, DOI: 10.1002/047134608X.

18. Tromba, D.; Munteanu, L.; Schneider, V.; Holzapfel, F. Approach trajectory generation using Bézier curves, 2015 IEEE International Conference on Aerospace Electronics and Remote Sensing Technology (ICARES), 3-5 Dec. 2015, DOI: 10.1109/ICARES.2015.7429835

19. Jalba, A.C.; Wilkinson, M.; Roerdink J. Shape representation and recognition through morphological curvature scale spaces, IEEE Trans Image Process, 200615 (2), pp. 331 - 341, DOI: 10.1109/TIP.2005.860606.

20. Prautzsch, H.; Boehm, W.; Paluszny M. Bézier and B-Spline Techniques, Spinger, Berlin, Germany, 2002, pp. 9 - 57, ISBN 3-540-43761-4.

21. 156 mm Monocrystalline Mono Solar Cell 6 x 6. Available online: https://www.aliexpress.com/item/50pcslot-4-6W-156mm-mono-solar-cells-6x6-150feet-Tabbing-Wire-15feet-Busbar-Wire-1pc/1932804007.html (accessed on 21 Sep 2017).

22. MünchenSolar M Series Monocrystalline MSMDxxxAS-36.EU Datasheet, https://cdn.enf.com.cn/Product/pdf/Crystalline/559cd7e85436f.pdf (accessed on 31 Jan 2018)

23. Mugnaini, D. Bézier Curve with draggable control points. Draw, manipulate and reconstruct Bézier Curves, version 1.11, Available online: https:/www.mathworks.com/matlabcentral/fileexchange/51046bézier-curve-with-draggable-control-points (accessed on 30 Dec 2017)

24. Garrity, M. Bézier Curves and Kronecker's Tensor Product, posted 13 October 2014, Available online: https://blogs.mathworks.com/graphics/2014/10/13/bézier-curves/, (accessed on 31 Dec 2017)

25. Khan, M. Cubic Bézier Least Square Fitting, version 1.4, https://www.mathworks.com/matlabcentral/fileexchange/15542-cubic-bézier-least-square-fitting, (accessed on 30 December 2017).

26. Wolberg, J. Data Analysis Using the Method of Least Squares. Extracting the Most Information from Experiments, 2006 Springer-Verlag Berlin Heidelberg, ISBN 978-3-540-25674-8, DOI 10.1007/3-540-31720-1

27. Hansen pC.; Pereyra V.; Scherer G. Least Squares Data Fitting with Applications, JHU Press, Baltimore, USA, 2013, ISBN 978-1-421-40786-9.

28. Shao, L.; Zhou, H. Curve Fitting with Bézier Cubics, in Graphical Models and Image Processing, Volume 58, Issue 3, May 1996, Pages 223-232, https://doi.org/10.1006/gmip.1996.0019.

29. Zhao, L.; Jiang, J.; Song, C.; Bao, L.; Gao, J., Parameter Optimization for Bézier Curve Fitting Based on Genetic Algorithm, in: Tan Y., Shi Y., Mo H. (eds) Advances in Swarm Intelligence, ICSI 2013, Lecture Notes in Computer Science, vol 7928. Springer, Berlin, DOI: https://doi.org/10.1007/978-3-642-38703-6_53.

30. Shell SP70 Photovoltaic Solar Module, Product Information Sheet, http://www.solenerg.com.br/files/SP70.pdf (accessed on 15 Mar 2018) 
31. Isofoton I-150 InDach Solar Panel specifications, http://www.posharp.com/i-150-indach-solar-panel-fromisofoton_p337595585d.aspx (accessed on 15 Mar 2018)

32. Bosch Solar Module c-Si M 60 Model M245 3BB, http://www.boschsolarenergy.de/media/us/alle_pdfs_1/technische_dokumente_3/datenblaetter_1/kristalline_module_6/p_6 0_eu30014_1/Bosch_Solar_Module_c_Si_M_60_EU30014_en_Europe.pdf (accessed on 16 Mar 2018) Solarenergie $\mathrm{GmbH}$

MSP300AS-36.EU, http://www.secondsol.de/handelsplatz/herstellerdatenblatt/photovoltaikmodule/Polykristallin/M\%C3\%B Cnchen\%20Solarenergie\%20GmbH/MSP300AS-36.EU.htm (accessed on 16 Mar 2018)

34. Kyocera KC200GT, High Efficiency Multicrystal Photovoltaic Module, https://www.kyocerasolar.com/dealers/product-center/archives/spec-sheets/KC200GT.pdf (accessed on 16 Mar 2018)

35. Kyocera KC85T, High Efficiency Multicrystal Photovoltaic Module, https://www.kyocerasolar.com/dealers/product-center/archives/spec-sheets/KC85T.pdf (accessed on 17 Mar 2018)

36. Kyocera KD245GH-4FB2 High Efficiency Multi-Crystalline Photovoltaic Module, http://www.australiansolar.com.au/images/KD245GH-4FB2.pdf (accessed on 17 Mar 2018) KD135SX_UPU

Technical

Data, http://www.datasheetspdf.com/pdf/846173/KYOCERA/KD135SX-UPU/1 (accessed on 17 Mar 2018)

38. Sharp ND-224UC1 $(224 \mathrm{~W}) \quad$ Solar Panel Technical Data, http://files.sharpusa.com/Downloads/Solar/Products/sol_dow_ND224UC1.pdf (accessed on 17 Mar 2018)

39. Shell Solar Revised 2nd Ed. http://www.efn-uk.org/l-street/renewables-lib/solar-reports/index_files/ShellSolar.pdf (accessed on 18 Mar 2018)

40. Solarex MSX-60 and MSX-64 Photovoltaic Modules Technical Data, https://www.solarelectricsupply.com/media/custom/upload/Solarex-MSX64.pdf (accessed on 18 Mar 2018)
41. Amerisolar AS-6P Technical
Data, https://www.acosolar.com/amfilerating/file/download/file_id/448/?__store=solar_all (accessed on 18 Mar 2018)

42. Sanyo HIT-240 HDE4 Technical Data, http://future-energy-solutions.co.uk/wpcontent/uploads/2014/10/Panasonic-Datasheet-HIT-240W.pdf (accessed on 18 Mar 2018)

43. Onyx 1200x600 ref10 Technical Data, http://onyxsolardownloads.com/docs/ALL-YOUNEED/Technical_Guide.pdf (accessed on 17 Mar 2018)

44. 6.5Wp L Cell a-Si cell Technical Data, https://www.enfsolar.com/pv/cell-datasheet/1696 (accessed on 19 Mar 2018) 